\title{
Individualized diversity in the extracellular metabolome of live human gliomas
}

Authors: Cecile Riviere-cazaux ${ }^{1}$, Lucas P. Carlstrom ${ }^{1}$, Karishma Rajani ${ }^{1}$, Amanda Munoz-casabella ${ }^{1}$, Jann N Sarkaria ${ }^{2}$, Moses Rodriguez ${ }^{3}$, Masum Rahman ${ }^{1}$, Desmond Brown $^{4}$, Jaclyn F White ${ }^{5}$, Samar Ikram ${ }^{1}$, Siobhan Chantigian ${ }^{1}$, Seth Ransom ${ }^{1}$, Renee Hirte $^{1}$, Arthur Warrington ${ }^{1,3}$, Ju-Hee H. $\mathrm{Oh}^{6}$, William F. Elmquist ${ }^{6}$, Jeanette E EckelPassow $^{7}$, Sani H. Kizilbash ${ }^{8}$, Terry C. Burns ${ }^{1}$

\section{Affiliations:}

Departments of ${ }^{1}$ Neurologic Surgery, ${ }^{2}$ Radiation Oncology, ${ }^{3}$ Neurology, ${ }^{7}$ Health Sciences Research, and ${ }^{8}$ Oncology, Mayo Clinic, Rochester MN, USA

${ }^{4}$ Neurosurgical Oncology Unit, Surgical Neurology Branch, National Institutes of Neurological Disorders and Stroke, National Institutes of Health, Bethesda, MD, USA

${ }^{5}$ Department of Neurologic Surgery, Wake Forest Baptist Health, Winston-Salem, NC, USA

${ }^{6}$ Brain Barriers Research Center, Department of Pharmaceutics, College of Pharmacy, University of Minnesota, Minneapolis, MN, USA

Corresponding Author

\author{
Terry Burns, M.D., Ph.D. \\ Department of Neurosurgery - Mayo Clinic \\ 200 First St SW \\ Rochester, MN, USA 55905 \\ burns.terry@mayo.edu
}

Funding: This work was supported by NINDS (NRCDP), the Minnesota Partnership for Biotechnology and Genomics, Mayo Clinic Cancer Center and Center for Individualized Medicine, U54 CA210180, the American Brain Tumor Association, Brains Together for the Cure, Humor to fight the Tumor, and Lucius \& Terrie McKelvey.

Conflict of Interest: We have no conflict of interest to disclose.

\section{Authorship:}

- Study design and conception: TB, CRC, LPC, KR, WFE

- Performed experiments: TB, CRC, LPC, KR, JFW, DB

- Analyzed data: TB, CRC, KR

- Critically reviewed and approved manuscript: All authors Word count: 


\begin{abstract}
Cancer metabolism is of increasing interest for drug development but few methods exist to evaluate live human malignancies. We utilized high molecular weight (HMW) microdialysis with elevated flow rate pumps under an investigational device exemption to sample the microenvironments of live human gliomas and adjacent brain during neurosurgical resections. Untargeted metabolic profiles spanning over 300 named metabolites were captured from $20 \mu \mathrm{L}$ of microdialysate representing 10 minutes of intra-operative collection time. Five patients were each analyzed via 3 catheters with analysis of $>300$ named metabolites and 5 drugs. Rankbased analyses and machine learning highlighted metabolic heterogeneity across and between patients, as well as marked metabolic convergence within the most aggressive regions of molecularly diverse tumors. A novel glioma-associated metabolite, guanidinoacetatic acid (GAA), topped the list of extracellular glioma metabolites reflecting altered amino acid and energy metabolism. Intraoperative HMW microdialysis offers improved opportunities to accelerate individualized translational progress for glioma.
\end{abstract}

Keywords: Glioblastoma (GBM), oligodendroglioma, microdialysis, metabolomics, IDH 
medRxiv preprint doi: https://doi.org/10.1101/2021.08.24.21262320; this version posted January 1, 2022. The copyright holder for this preprint (which was not certified by peer review) is the author/funder, who has granted medRxiv a license to display the preprint in perpetuity.

All rights reserved. No reuse allowed without permission.

\section{INTRODUCTION}

Diffuse infiltrative gliomas, including astrocytomas and oligodendrogliomas, comprise most adult primary malignant brain tumors. While survival varies by grade and molecular subtype, all remain incurable, regardless of the best available therapies. Glioblastomas (WHO grade 4 astrocytomas) are the most common and carry a median survival of 15 months ${ }^{1}$. Isocitrate dehydrogenase (IDH) mutations occur in all oligodendrogliomas and a subset of astrocytomas, affording improved prognosis due to typically slower growth and more favorable response to standard-of-care radiation and alkylating chemotherapy ${ }^{2,3}$. Highlighting the dismal rate of therapeutic progress, the last drug found to improve survival for gliomas was temozolomide in $2005{ }^{1}$. Glioma heterogeneity among patients hampers therapeutic generalizations across diverse patient cohorts. Moreover, profoundly diverse genetic, epigenetic, and metabolic phenotypes accumulate within individual patients' tumor ecosystems ${ }^{4-6}$. Such heterogeneity has hampered therapeutic efforts to target glioma-associated mutations. Conversely, divergent gliomas may nonetheless leverage convergent metabolic survival strategies in the setting of nutrient deprivation, genotoxic stress, and growth requirements common across tumors ${ }^{7,8}$. As such, several features of glioma metabolism are increasingly viewed as promising therapeutic targets. Few strategies currently exist to characterize the metabolic landscape of human gliomas in vivo.

Microdialysis has been used to quantify human extracellular biomarkers of traumatic and hypoxic brain injury in neurocritical care units. Microdialysis is also a well-established method to quantify CNS drug delivery in early phase clinical trials ${ }^{9-12}$. However, no study has used microdialysis to acutely explore live human gliomas. All trials thus far have performed microdialysis at slow flow rates over multiple days, limiting practical deployment and rapid insights in most neuro-oncological settings. We initiated a pilot feasibility study leveraging high molecular weight (HMW) microdialysis catheters to determine whether the extracellular metabolic signatures within diverse regions of live human gliomas could reliably be evaluated intraoperatively, immediately prior to resection in a practical 20-minute window of opportunity. Untargeted metabolomic analysis performed on only $20 \mu \mathrm{L}$ (10 minutes) of microdialysate conveyed multiple layers of data spanning tumor mutational status, radiographic localization, individual metabolic landscape, and relative levels of multiple pharmacologic agents. We further compared intraoperatively sampled microdialysate to intraoperatively sampled CSF and external data sets. We found that rank-based analyses of metabolite fold changes between each patient's unique tumor and brain can augment $n=1$ analyses, despite the variability of individual metabolites across patients. Our findings provide evidence for both divergent and convergent 
medRxiv preprint doi: https://doi.org/10.1101/2021.08.24.21262320; this version posted January 1, 2022. The copyright holder for this preprint (which was not certified by peer review) is the author/funder, who has granted medRxiv a license to display the preprint in perpetuity.

All rights reserved. No reuse allowed without permission.

metabolism within and between live human brain tumors and suggest that IDH status alone is insufficient to predict the global extracellular metabolic signature of live human gliomas. Our study demonstrates that intraoperative microdialysis can feasibly be deployed within the setting of one surgery to allow for previously unleveraged explorations of the metabolic landscape of diverse human gliomas.

\section{RESULTS}

\section{Feasibility of intraoperative microdialysis}

Microdialysis procedures were completed during the course of clincally indicated tumor glioma resections, with all catheters removed by the end of surgery. One patient (Astro-mut) was discharged to inpatient rehabilitation prior to returning home. All other patients were discharged home on post-operative day 2. No complications occurred. Intraoperative and postoperative management were not impacted by participating in the study.

\section{Elevated D2-Hydroxyglutarate (D-2-HG) in IDH-mutant tumor microdialysate}

D-2-HG is markedly elevated in IDH-mutant gliomas and remains one of the bestcharacterized glioma oncometabolites. To determine if D-2-HG levels in microdialysate are quantitatively reflective of IDH status, we utilized $10 \mu \mathrm{L}$ of a $40 \mu \mathrm{L}$ microdialysate sample to quantify D-2-HG via targeted metabolomic analysis. D-2-HG was elevated in microdialysate from IDH-mutant as compared to IDH-wild-Type (WT) tumors (median: 27.29 versus $0.63 \mu \mathrm{M}$; Fig 1D and supplemental data). Patient Astro ${ }^{4-m u t}$ showed a $>1000 x$ difference in D2-HG between non-enhancing tumor (FLAIR) and adjacent brain (831.80 versus $0.68 \mu \mathrm{M}$; Fig 1D). Maximal microdialysate D2-HG levels from IDH-mutant tumors exceeded those from intraoperatively collected CSF when available (9.3-fold in Oligo $^{2}$ and 63-fold in Astro ${ }^{4-m u t ~ F i g ~ 1 D ; ~}$ supplemental data), consistent with highest D-2-HG production directly within the tumor. These data demonstrated the feasibility of intraoperative HMW microdialysis to quantify a dialyzable oncometabolite during standard-of-care surgery for tumor resection.

Untargeted metabolomics is increasingly leveraged to gain more comprehensive insights regarding the global metabolome. We utilized $20 \mu \mathrm{L}$ of microdialysis from each catheter for untargeted metabolomic analysis via the Metabolon platform ${ }^{13}$. Untargeted analysis reported total D-2-HG. These were plotted against the combined stereoisomer (D-2-HG + L-2-HG) levels from targeted analyses yeilding a robust correlation $\left(R^{2}=0.9989\right)$ between the two platforms across 2,500-fold concentration range (Fig 1E), suggesting feasible quantitative comparisons from untargeted metabolomic data. 
medRxiv preprint doi: https://doi.org/10.1101/2021.08.24.21262320; this version posted January 1, 2022. The copyright holder for this preprint (which was not certified by peer review) is the author/funder, who has granted medRxiv a license to display the preprint in perpetuity.

All rights reserved. No reuse allowed without permission.

\section{Global metabolomics reveal a dynamic glioma-versus-brain environment}

Over 300 unique named metabolites were identified across all microdialysate samples (see Supplemental Data for the complete data set). We began by assessing named metabolites present in at least half of the catheters (297 metabolites). As with 2-HG (Fig 1E), we used the relative abundance of each metabolite based on raw peak areas to compare the presence of each metabolite in tumor versus adjacent brain microdialysate. All catheters for patients $\mathrm{Oligo}^{2}$ and $\mathrm{Oligo}^{3}$ were placed within non-enhancing tumor. However catheter $\mathrm{C}$ for Oligo $^{3}$ was in the infiltrative margin of the lesion (FLAIR-Brain) enabling relative comparisons between Catheters $A$ and $C$. We ranked metabolites based on fold change between enhancing tumor and brain microdialysate (catheter $A$ versus $C$ in Astro ${ }^{4-m u t}, G B M^{\mathrm{TW}} 1$, and $\mathrm{GBM}^{\mathrm{WT}} 2$ ) or between FLAIR and FLAIR-Brain $\left(\mathrm{Oligo}^{3}\right.$ ), to determine which metabolites were most abundant in tumor versus brain for each of these four patients (Supp Figure 1).

To enable quantitative comparisons across patients, we restricted analysis to those metabolites detected in microdialysate from each of 15 catheters $(n=181)$. The ranked order of metabolite fold changes between enhancing tumor and brain followed a similar pattern across the three patients with enhancing tumors (Astro ${ }^{4-m u t}, G B M^{W T} 1$, and $G_{B M}{ }^{W T} 2$; Fig 2A). The top tumor-defining metabolites based on fold-change were guanidinooacetate (GAA) (A/C FC in Astro $^{4-m u t}, \mathrm{GBM}^{\mathrm{WT}} 1$, and $\mathrm{GBM}^{\mathrm{WT}} 2=81.2,3.27,122.4$, respectively), $\mathrm{N}(6)$-Methyllysine ( $\mathrm{FC}=$ 6.47, 4.34, and 7.22, respectively), and Proline ( $F C=22.9,3.21,8.20$, respectively). Tumorassociated metabolic pathways included various amino acid metabolic pathways, including leucine and lysine. The top brain metabolites included D-arabitol $(F C=0.05,0.37,0.10$, respectively), ribonic acid ( $\mathrm{FC}=0.02,0.72,0.07$, respectively), and 2,3-dihydroxy-5-methylthio4-pentenoic acid (DMTPA) $(F C=0.03,0.51$, and 0.13 , respectively), in addition to wellestablished brain-associated metabolites including $\mathrm{N}$-acetyl aspartate $(\mathrm{FC}=0.26,0.62$, and 0.11 , respectively) and $\mathrm{N}$-acetylaspartylglutamic acid (NAAG) ( $\mathrm{FC}=0.21,0.42,0.11$, respectively). Brain-associated metabolic pathways included aminosugar, pentose, and glutamate metabolism.

Despite a reproducible pattern of tumor- and brain-associated metabolites, the relative magnitude of metabolite fold changes between enhancing tumor and brain varied substantially. Patients Astro ${ }^{4-m u t}$ and $\mathrm{GBM}^{\mathrm{WT}} 2$ each had maximal metabolite fold changes $>40 \mathrm{x}$, but no metabolite for patient $\mathrm{GBM}^{\mathrm{WT}} 1$ exceeded a FC of 5 between tumor and brain (Fig 2B). The ranked fold change metabolite list comparing catheters $A$ versus $C$ for patient Oligo $^{3}$ revealed a similar pattern to that observed in the three astrocytomas (Fig 2A), suggesting at least some 
medRxiv preprint doi: https://doi.org/10.1101/2021.08.24.21262320; this version posted January 1, 2022. The copyright holder for this preprint (which was not certified by peer review) is the author/funder, who has granted medRxiv a license to display the preprint in perpetuity.

All rights reserved. No reuse allowed without permission.

overlap in the metabolic signature across glioma subtypes. We also asked if a comparable pattern could be seen in the non-enhancing (B; FLAIR) catheters versus brain for patients with astrocytomas. A variably robust signature, strongest in patient Astro ${ }^{4 m u t}$, weakly discernible in patient $\mathrm{GBM}^{\mathrm{WT}} 1$, and absent in patient $\mathrm{GBM}^{\mathrm{WT}} 2$ was observed (Fig 2A). Likewise, the ranked fold change metabolite list of catheter $B$ versus $C$ revealed a dynamic range of metabolites across patients, with the highest and lowest FCs observed in patient Astro ${ }^{4-m u t}$ (highest: GAA, $\mathrm{FC}=1585$; lowest: NAAG, $\mathrm{FC}=0.03$ ) (Fig 2C). In summary, enhancing and nonenhancing/FLAIR tumor microdialysate exhibited unique metabolic signatures with some commonalities and dynamic fold changes of metabolites between tumor and brain.

\section{Individualized signatures of tumor versus brain enriched across patients}

Prior work by Björklbom et al. ${ }^{14}$ reported a metabolic phenotype of glioblastoma microdialysate compared to that of adjacent brain. However, these studies were performed over several days, whereas our samples were collected acutely during surgery. To determine if acute intraoperative sampling of the in vivo global metabolome via microdialysis could yield comparable results to that of prolonged catheter placements, we compared the fold changes from their analysis for the 28 significantly tumor- or brain-associated that were also detected in each of our 15 catheters. Obvious discrepancies were only noted in 3 of 28 metabolites (Fig 3A). Although we did not have an ideal "brain" catheter for either oligodendroglioma, the direction of tumor-associated metabolite changes from astrocytomas was conserved in patient Oligo $^{3}$-albeit less so in the Oligo ${ }^{3}$ Catheter A versus $C$ comparison. Conversely, only one of the five brain-associated metabolites (NAA) was lower in catheter $A$ than catheter $C$ for patient Oligo $^{3}$ (Fig 3A).

To more rigorously and quantitatively compare metabolic phenotypes between catheters and between patients, we turned to Gene Set Enrichment Analysis (GSEA), the most widely utilized rank-based bioinformatic enrichment algorithm. Although generally applied to genebased analyses, we repurposed this for metabolomic analysis. Using GSEA, we selected the top and bottom 50 metabolites based on fold change from each comparison and determined where these metabolites fell in the ranked metabolite lists for the remaining three patients (Supplemental Data). Each patient's individual tumor signature was robustly and positively enriched in the ranked list of tumor versus brain metabolites from other patients (Fig 3B). Conversely, the brain signatures were negatively enriched in these same patient-specific tumor versus brain metabolite lists, consistent with a conserved metabolic signature of tumor versus brain across patients (Fig $\mathbf{3 C}$ ). Leveraging these individual patient-level data, metabolite 
medRxiv preprint doi: https://doi.org/10.1101/2021.08.24.21262320; this version posted January 1, 2022. The copyright holder for this preprint (which was not certified by peer review) is the author/funder, who has granted medRxiv a license to display the preprint in perpetuity.

All rights reserved. No reuse allowed without permission.

enrichment between patients proved highly robust with a False Discovery Rate (FDR) of 0.000 for most interpatient comparisons (Fig 3D) of tumor versus brain metabolites. Importantly, the previously published metabolic signature of tumor versus adjacent brain from Björkblom et al ${ }^{15}$ was strongly enriched at FDR of 0.004 or less for each of the three astrocytomas, and 0.015 for Olig $^{3}$ (Fig 3D). In summary, intraoperative microdialysis revealed a conserved global tumor versus brain signature in extracellular fluid, which could be quantified and statistically evaluated at the level of individual patients.

\section{Comparative analyses using $25 \%$ standards and CSF}

Generating an in vivo extracellular metabolome as discussed above requires intraoperative access to both tumor and adjacent brain. Although the three catheters for patient Oligo $^{2}$ were each placed in divergent locations, none was relatively more or less "tumor" than another. Adjacent less tumor-infiltrated brain structures served language and motor functions and were thus excluded from surgical sampling, leaving the metabolic phenotype of Oligo ${ }^{2}$ poorly defined. We therefore defined an external standard reference to which each of the 15 catheters could be compared independently of any other catheter from the same patient. To help minimize reference bias due to disproportionate numbers of specific tumor types or sample locations within our 15 -catheter cohort, we selected the $25^{\text {th }}$ percentile peak area (between minimum and median) from the 15-catheter data set for each metabolite. Ranked metabolite lists were then generated for the fold change between each catheter and the " $25 \%$ reference." The top 50 metabolites thereby generated for each catheter were utilized for enrichment analysis. To maintain consistency in analysis, we looked for enrichment of these metabolite lists within the ranked metabolite lists comparing tumor to brain (Fig 3D). We observed strong positive enrichment for tumor catheter metabolite sets generated using the $25 \%$ standard within tumor versus brain ranked metabolite lists and negative enrichment for brain metabolite sets (Fig 4A). Substantial variability was observed within the "B" catheters, some of which were enriched for tumor, while others were more strongly enriched for brain (Supplemental Data). Consistent with the lower-grade phenotype of patient Oligo $^{2}$, more brain-like (negative) enrichment was observed for patient Oligo $^{2}$ catheters in the tumor versus brain ranked metabolite lists for patients Astro ${ }^{4 m u t}$ and $\mathrm{GBM}^{\mathrm{WT}} 2$.

Prior metabolomic analyses have utilized an internal patient reference other than normal brain, such as venous blood ${ }^{16}$. Since patients with brain tumors generally have a higher total number of non-malignant than malignant cells in the CNS, we reasoned that cerebrospinal fluid (CSF) may provide a relevant intrapatient internal reference relatively enriched for normal CNS- 
medRxiv preprint doi: https://doi.org/10.1101/2021.08.24.21262320; this version posted January 1, 2022. The copyright holder for this preprint (which was not certified by peer review) is the author/funder, who has granted medRxiv a license to display the preprint in perpetuity.

All rights reserved. No reuse allowed without permission.

associated metabolites. CSF was accessible from the surgical field in four out of five patients (all except patient Oligo $^{3}$ ). CSF samples (100 $\mu \mathrm{L}$ each) were analyzed via untargeted metabolomic analysis on the Metabolon platform in parallel to the microdialysate. Of the 181 named metabolites present in all 15 catheters, 166 metabolites were also detected in all four CSF samples (Supplemental Data). Using a similar enrichment analysis as in Figures 3B-D and $4 A-B$, ranked lists of the microdialysate (Cath $A$ ) versus the patient's own CSF were generated and evaluated for enrichment of the tumor and brain signatures. Results were similar to those found when Catheter A was compared to the $25 \%$ standard, although each patients' tumor and brain signatures were less reproducibly found when CSF was used as a comparator (Fig 4B).

Enrichment analyses indicated a reproducible metabolome for tumor versus brain across patients (Fig 3D and 4). Moreover, in absence of an internal "brain" reference, CSF and 25\% standards may be used to help analyze the metabolite signature of an individual catheter. To help visualize the relative analytic performance of each strategy across all 15 catheters, we utilized a strategy akin to "peer review." For each patient, a tumor versus brain ranked metabolite list was generated, comprising of all other available patients (peers). To avoid circular reasoning, data from the individual patient was excluded from consideration in generating the ranked metabolite list. Next, the top 30 metabolites from each of the three analytic strategies (catheter versus catheter, catheter versus $25 \%$, and catheter versus CSF) were plotted based on their rank in the consensus "peer review" ranked metabolite list (Fig 4C). In patients Astro ${ }^{4-m u t}$ and $\mathrm{GBM}^{\mathrm{WT}} 1$, the $25 \%$ standard and CSF comparator strategies accurately identified placement of catheter A within tumor--albeit with a slightly lower median rank. Across catheters, the $25 \%$ standard generally more closely approximated catheter versus catheter comparisons than CSF versus catheter analyses. Top metabolites in the brain versus CSF analyses particularly failed to rank near the brain end of the peer review list-likely due the brain metabolome being less distinct from CSF than the tumor metabolome. Patient GBM $^{\mathrm{WT}} 1$ showed a lower metabolite fold-change between brain versus tumor than the other two patients with astrocytomas (Fig $\mathbf{2 C}$ ). In agreement with this, patient GBM $^{\text {WT }} 1$ 's enhancing tumor catheter (Fig 4C) appeared less enriched for tumor than the other two astrocytomas based on CSF and $25 \%$ standard comparisons. Evidence for a more "brain"-like FLAIR catheter in patient GBM ${ }^{\mathrm{WT}} 1$ than either other astrocytoma patient was conveyed by all three modalities of analysis (FLAIR). Patient Oligo $^{2}$ had three catheters all placed in FLAIR+ tumor, precluding meaningful catheter versus catheter analysis. CSF was not available for patient Oligo ${ }^{3}$. Nevertheless, findings for most catheters based on available analyses tended to suggest a relatively intermediate 
medRxiv preprint doi: https://doi.org/10.1101/2021.08.24.21262320; this version posted January 1, 2022. The copyright holder for this preprint (which was not certified by peer review) is the author/funder, who has granted medRxiv a license to display the preprint in perpetuity.

All rights reserved. No reuse allowed without permission.

phenotype between brain and tumor (lower rank), as expected for catheters placed in lower grade non-enhancing tumors. In summary, use of an external 25\% standard reference may help to discern the relative placement of a single catheter within brain versus tumor. Conversely, use of an internal CSF standard proved the least robust of the three approaches to discriminate the tumor versus brain signature of single catheter microdialysate.

\section{Microdialysate reflects the intraoperative story}

Multiple drugs and their metabolic derivatives were present within the 315 named metabolites identified in untargeted analysis. Patients routinely receive levetiracetam (Keppra), cefazolin (Ancef), and mannitol peri- and intra-operatively, each of which was detected in the 20 $\mu \mathrm{L}$ microdialysate.

Keppra is a CNS-penetrant anti-epileptic medication routinely administered to decrease the risk of intraoperative or postoperative seizures. Consistent with this, Keppra was detected in 12 of 12 microdialysate samples from patients who received Keppra. Patient Oligo ${ }^{3}$ did not receive it due to a reported allergy (Fig 5A). We were interested to note that Keppra levels varied by as much as $2 x$ within individual patients, given that Keppra is CNS penetrant and should equally permeate throughout the brain. We hypothesized that this may be due to varying levels of recovery across the catheters due to either variable tissue resistance to diffusion across locations or other technical factors. No absolute standard was available to quantify recovery across catheters, and given expected heterogeneity across catheters, we normalized to the median of the 10 least variable metabolites, as determined by coefficient of variance. This normalization visibly decreased the variance of Keppra levels within and between patients (Fig 5A-B).

Cefazolin (Ancef) is administered as a preoperative antibiotic and, in contrast to Keppra, has poor CNS penetration. Contrast-enhancing regions of high-grade gliomas exhibit a relatively impaired blood brain-barrier. Consistent with this, Ancef was only identified in microdialysate from two catheters, both of which were placed in regions of contrast enhancing tumor in patients with grade 4 astrocytomas. The third patient with a grade 4 astrocytoma was not administered Ancef due to a reported penicillin allergy (Fig $\mathbf{5 C}$ ). Importantly, the failure to recover any quantifiable Ancef in the microdialysate of 10 of 10 catheters placed outside of enhancing tumor suggests that intraoperative placement of microdialysis catheters does not cause sufficient disruption of the blood brain barrier to enable robust detection of a CNS non-penetrant drug.

Mannitol is often administered intraoperatively to mitigate cerebral edema and brain swelling. Mannitol was only administered to patients Oligo and Astro ${ }^{4-m u t}$. Mannitol peak areas 
medRxiv preprint doi: https://doi.org/10.1101/2021.08.24.21262320; this version posted January 1, 2022. The copyright holder for this preprint (which was not certified by peer review) is the author/funder, who has granted medRxiv a license to display the preprint in perpetuity.

All rights reserved. No reuse allowed without permission.

were higher across all three catheters in these two patients when compared to those who were not administered mannitol (Fig 5D). Additionally, four of the five surgeries were performed awake (all except patient Astro ${ }^{4-m u t}$ ). Acetaminophen is often administered during awake craniotomies to prevent any intraoperative pain that may occur, despite the use of analgesics and lack of pain sensation in the brain. Intraoperatively administered acetaminophen could be quantified in the three patients who received it. It was detectable at lesser amounts in patient Astro $^{4-m u t}$, potentially due to nondocumented preoperative administration (Fig 5E). Caffeine levels were markedly higher in each of the awake patients than the one patient for whom surgery was performed asleep. Patients must fast from midnight prior to surgery, typically preventing coffee-drinking patients from consuming their usual morning coffee. As such, three of the awake patients were provided intravenous caffeine during surgery to facilitate participation in awake cognitive mapping/monitoring tasks (Fig 5F). Patient GBM $^{\mathrm{WT}} 2$ did not receive caffeine intraoperatively, raising the question of why we observed elevated caffeine levels in all three microdialysis catheters. However, when queried, the patient admitted to drinking a cup of black coffee in the early morning prior to surgery. Collectively, these data suggest that acute intraoperative microdialysis paired with metabolomics may provide an efficient avenue to simultaneously evaluate relative extracellular free drug levels for multiple pharmacologic agents in multiple locations from only $20 \mu \mathrm{L}$ of microdialysate.

\section{Correlation and clustering analyses}

Finally, despite the relatively small sample size of 15 microdialysates, we asked what groupings may be revealed by machine learning algorithms using the global metabolomic signatures of 181 consistently detected metabolites across the 15 samples. To provide an overview of the metabolic data collected, Spearman correlation maps were generated based on unsupervised hierarchical clustering between the 181 metabolites (Fig 6A) and 15 samples (Fig 6B). Samples from patients Oligo $^{2}$, Oligo $^{3}$, and GBM $^{\mathrm{WT}} 1$ each clustered separately by patient. However, samples for Astro ${ }^{4-m u t}$ and $\mathrm{GBM}^{\mathrm{WT}} 2$, clustered together with the two enhancing $(\mathrm{E})$ and the two Brain $(B)$ catheters each juxtaposed. When the data was dimensionally reduced using Principal Component Analysis (PCA), each patients' catheters tended to cluster together (Fig 6C), and no separation was observed between samples from IDH-mutant versus IDH-WT gliomas (Fig 6D). Clustering analysis using sparse Partial Least Squares Discriminant analysis (sPLS-DA) supervised by IDH-phenotype, enabled robust separation of IDH-WT from IDHmutant gliomas in the first component, accounting for $11 \%$ of total variance (Fig 6F). Conversely, sPLS-DA supervised by patient identity clustered samples by astrocytoma versus 
medRxiv preprint doi: https://doi.org/10.1101/2021.08.24.21262320; this version posted January 1, 2022. The copyright holder for this preprint (which was not certified by peer review) is the author/funder, who has granted medRxiv a license to display the preprint in perpetuity.

All rights reserved. No reuse allowed without permission.

oligodendroglioma in the first component (19.6\% of variance) and grade in the second component (16.9\% of variance) (Fig 6E). All patients with grade 4 astrocytomas showed overlapping 95\% confidence clouds. Despite the fact that one patient's tumor was an IDHmutant (recurrent) and another was IDH-WT, immediately adjacent positioning of the Astro ${ }^{4-m u t}$ and $\mathrm{GBM}^{\mathrm{WT}} 2$ enhancing and brain catheters in SPLS-DA (Fig 6E) mirrored their proximity in the Spearman analysis (Fig 6B).

\section{DISCUSSION}

We tested the feasibility of intraoperative microdialysis to acutely evaluate the extracellular metabolome within live human gliomas immediately prior to resection. Leveraging this previously untapped window of opportunity, within one surgery and with only 20-minute aliquots, we demonstrate: 1) robustly elevated D-2-HG in IDH-mutant glioma microdialysate; 2) rank-based metabolic features that reproducibly separate tumor from brain across phenotypically diverse tumors; 3) relatively improved performance of tumor and brainmicrodialysate-based standards over CSF to discern the relative tumor burden of individual catheters; 4) concurrent intratumoral analysis of at least five different intraoperatively administered drugs across multiple tumor regions; and 5) clustering of global metabolic phenotypes which are driven more by patient identity and tumor subtype than IDH status.

\section{Acute intraoperative microdialysis: a previously untapped 20-minute window into tumor metabolism}

Acute intraoperative microdialysis in a practical 20-minute timeframe yielded relative levels of hundreds of metabolites for targeted and untargeted metabolomics analyses in five patients with genomically and molecularly diverse gliomas. Increasing preclinical evidence suggests the potential therapeutic utility of targeting cancer-associated metabolic vulnerabilities. In contrast to the profound genomic heterogeneity seen within and across malignancies, a more finite set of convergent metabolic strategies might be deployed to meet the unavoidable bioenergetic demands of tumor metabolism ${ }^{17}$ in the face of genomic instability ${ }^{18,19}$, oxidative stress $^{20}$, hypoxia ${ }^{21}$, and nutrient deprivation ${ }^{22,23}$. Microdialysis surprisingly revealed a highly conserved and reproducible tumor metabolic signature, most strongly observed in two patients (Astro $^{4-m u t}$ and $\mathrm{GBM}^{\mathrm{WT}} 2$ ) who differed across every technical and clinical parameter (Supplemental Table 1). Moreover, our rank-based analyses enabled multiple acutely and intraoperatively sampled patients to each independently confirm a set of glioma versus brainassociated metabolites identified in a previously published chronic microdialysis study (Fig 
medRxiv preprint doi: https://doi.org/10.1101/2021.08.24.21262320; this version posted January 1, 2022. The copyright holder for this preprint (which was not certified by peer review) is the author/funder, who has granted medRxiv a license to display the preprint in perpetuity.

All rights reserved. No reuse allowed without permission.

3A,D; $\left.{ }^{15}\right)$. Conditions in that study varied significantly from ours, as it was performed by an independent team on a different continent, using catheters implanted for multiple days. From only $20 \mu \mathrm{L}$ of microdialysate, a similar extracellular glioma metabolome was once again found, further highlighting its strong and reproducible signature. Such interpatient and interstudy reproducibility in the tumor-versus-brain extracellular metabolome suggests potential therapeutically-targeted convergencies in glioma metabolic survival strategies. Leveraging neurosurgical access to live human gliomas via microdialysis may enable longitudinal pharmacodynamic studies within catheter-implanted patients for whom pre-treatment baselines afford internal controls over several days to accelerate translational therapeutic progress ${ }^{14,15}$.

\section{Individualized controls}

One recent intraoperative study compared the metabolomic profile of venous blood draining live gliomas during surgery to peripheral venous blood (from the foot), normalizing each against arterial blood ${ }^{16}$. Encouraged by such intraoperative studies on live glioma metabolism, we explored the individualized differential metabolism of live human tumor versus brain using each patient as their own control in the setting of one surgery. However, such internal controls were not always feasible given the highly infiltrative nature of gliomas. As such, we assessed use of a CSF reference within individual patients and found it may struggle to discriminate regions of moderate tumor burden (e.g. FLAIR), from adjacent brain (Fig 4C). Multiple studies have analyzed metabolites present within the CSF of patients with gliomas ${ }^{24,25}$. While CSF is likely more representative of the altered glioma metabolome than blood given its proximity to the tumor, the CSF metabolome will predictably be diluted by the comparatively much higher total volume of brain than tumor, potentially obscuring glioma metabolomics. When intraoperative access to brain parenchyma for in vivo sampling is not feasible, we found that a consensus $25 \%$ reference standard could provide an external comparator to elucidate relative enrichment for tumor metabolites within a single patient. Whether this approach could be extended across samples processed in different batches requires further empiric testing. In summary, of the key lessons learned through this pilot study is the importance of a reference catheter within relatively normal brain to discern the tumor metabolome.

\section{Concurrent pharmacologic analyses}

We had not originally planned to quantify pharmacologic agents. However, five drugs administered in the operating room prior to microdialysis (levetiracetam, cefazolin, acetaminophen, mannitol, and caffeine) matched profiles from the Metabolon library, enabling 
medRxiv preprint doi: https://doi.org/10.1101/2021.08.24.21262320; this version posted January 1, 2022. The copyright holder for this preprint (which was not certified by peer review) is the author/funder, who has granted medRxiv a license to display the preprint in perpetuity.

All rights reserved. No reuse allowed without permission.

relative quantifications. To our knowledge, no prior study has evaluated any of these drugs in human tumor or brain microdialysate. The complete absence of three of five drugs in all samples from at least one patient supports the specificity of findings. For all drugs, elevated levels could be explained by administration documented in the medical record, apart from one patient whose coffee intake the morning of surgery was only discovered in retrospect. Interestingly, the absence of cefazolin (a non-CNS-penetrant drug) from all catheters placed outside of enhancing tumor suggests the feasibility of acute intraoperative microdialysis without marked disruption of the blood brain barrier. Given the common administration of these drugs in neurosurgical procedures, further pharmacokinetic characterization may empower use of these or similar agents as reference standards for early phase window-of-opportunity studies evaluating other novel drugs.

Neurosurgical phase 0 studies typically evaluate tissue levels of a single drug, but combination therapies may be needed. Our data suggest feasible analysis of extracellular free drug levels across multiple dialyzable drugs simultaneously in multiple locations within the setting of one surgery. Since drug analyses were not part of the original experimental design, concurrent drug levels from systemic circulation were not available to report brain-plasma ratios. However, future intraoperative studies leveraging systemic, tissue, and microdialysate drug levels may empower in vivo pharmacodynamic and pharmacokinetic characterization of drugs to maximize translational efficacy of candidate drugs and combinatorial therapies. Additionally, although we assessed only a single timepoint, dedicated pharmacokinetic microdialysis studies typically quantify drug levels across multiple days. Combining longitudinal pharmacokinetic and metabolomic analyses may reveal candidate pharmacodynamic biomarkers to discern target engagement, therapeutic impact, and induced mechanisms of therapeutic resistance.

\section{IDH status versus global metabolic phenotype}

IDH-mutant gliomas epitomize the oncogenic relevance of altered metabolism. We found elevated D-2-HG in the CSF and microdialysate in IDH-mutant tumors (Fig 1D and 1E). Maximal levels of D-2-HG were markedly higher in microdialysate than in CSF, highlighting the value of sampling candidate metabolic biomarkers directly at the source. D-2-HG was previously used as a pharmacodynamic biomarker for IDH inhibitors in tissue ${ }^{26}$ and via MRS ${ }^{27-29}$. Our observations suggest that monitoring of extracellular D-2-HG via microdialysis could provide an additional tool to augment early phase translation of novel therapies. Importantly, although IDHmutations are thought to drive early tumorigenic metabolic and epigenetic changes, the global extracellular metabolome of patients $A_{s t r o}^{4-m u t}$ and $\mathrm{GBM}^{\mathrm{WT}} 2$ were remarkably and robustly 
medRxiv preprint doi: https://doi.org/10.1101/2021.08.24.21262320; this version posted January 1, 2022. The copyright holder for this preprint (which was not certified by peer review) is the author/funder, who has granted medRxiv a license to display the preprint in perpetuity.

All rights reserved. No reuse allowed without permission.

similar across all analyses, from metabolite set enrichment and Spearman correlations to machine learning algorithms. Such metabolic similarities suggest that despite markedly elevated D-2-HG production, IDH-mutant astrocytomas can evolve into lesions which are otherwise almost metabolically indistinguishable from IDH-WT astrocytomas.

To our knowledge, our data report on a larger number of extracellular metabolites than any prior study specifically evaluating the live human glioma extracellular microenvironment. Many of the tumor-associated metabolites confirm metabolic disruptions previously associated with cancer biology. For example, amino acids, including proline, tyrosine, and valine, and their derivates, were more abundant in tumor than brain microdialysate. Accumulation of these metabolites may suggest an adaptive response to nutrient deprivation observed in gliomas ${ }^{30-32}$ and other cancers ${ }^{33}$. Multiple carnitine family metabolites were among the top tumor-associated metabolites (Supp Fig 1) and have been linked to energy production via fatty acid oxidation in glioma $^{34,35}$. The top tumor-associated metabolite in our data was guanidinoacetate (GAA) (Fig 2A), which accumulates in patients with GAMT deficiency, leading to impaired creatine production, seizures, and cognitive impairment ${ }^{36}$. To our knowledge, GAA elevation has not previously been reported in glioma, perhaps reflecting infrequent analysis of extracellular metabolites. Since GAA was identified via untargeted metabolomic analysis, further targeted metabolomic studies will be needed to validate this potentially novel candidate glioma biomarker. If confirmed, longitudinal monitoring of GAA may augment translational studies targeting glioma-enriched bioenergetic pathways. It is worth noting that both GAA and D-2-HG were higher in the FLAIR than enhancing tumor in Astro ${ }^{4-m u t}$, suggesting some tumor metabolites may either be lost down a disrupted blood brain barrier or may be produced at lower levels in relatively more necrotic tumor regions of tumor.

Finally, sPLS-DA suggests a potential metabolic dichotomy between astrocytomas and oligodendrogliomas (Fig 6E). Coincidentally, both patients with oligodendroglioma were females, while the other patients were males. Further work will be needed to discern 1) if the observed glioma subtype clustering is reproducible, 2) the extent to which patient gender and tumor grade may contribute to metabolic phenotype, and 3) which metabolites are most strongly associated with each pertinent clinical variables within and between patients. Additionally, future studies will be needed to directly compare the extracellular versus tissue metabolome and to incorporate metabolomic insights into a multi-omic portrait of dynamic inter- and intra-tumoral heterogeneity.

\section{Conclusion: toward individualized metabolic insights}


medRxiv preprint doi: https://doi.org/10.1101/2021.08.24.21262320; this version posted January 1, 2022. The copyright holder for this preprint (which was not certified by peer review) is the author/funder, who has granted medRxiv a license to display the preprint in perpetuity.

All rights reserved. No reuse allowed without permission.

In conclusion, we have shown that intraoperative microdialysis for tumor metabolomics is feasible and empowers previously unleveraged access to each patient's diverse tumor extracellular metabolome within the setting of one surgery. This strategy simultaneously enabled analysis of IDH status, metabolic phenotype, tumor region, and intraoperatively administered pharmacological agents within a practical 20-minute timeframe. Further work in larger cohorts will be needed to elucidate the full array of metabolic signatures observable within and between gliomas and their dynamic multi-omic correlates. Comparing tumor to adjacent brain across multiple patients, in conjunction with rank-based enrichment analyses, revealed reproducible quantifiable measures of tumor phenotype and relative burden within individual patients. This individualized framework wherein each patient can serve as their own control may empower expeditious translational pipelines to assess pharmacodynamic responses to novel, individualized, and combination therapies in tandem with multi-drug pharmacokinetic analyses.

These patients-each of whom remain alive at the time of this writing-understand the formidable odds of their disease. They all lead unique lives and have loved ones, including young children, families, and close friends. We present their raw data as a first installment toward what we intend to be a growing collaborative, open-source repository of individualized data from live human gliomas. We (both patients and investigators) hope that the data and insights shared can help inspire novel translational paradigms. By leveraging neurosurgical access to live human disease, we hope to accelerate tangible progress within the lifetimes of individual patients.

\section{MATERIALS AND METHODS}

\section{Patient Cohort and Study Design}

All study procedures were approved by the Mayo Clinic IRB. Patients provided written informed consent to participate in NCT04047264--an ongoing study evaluating the safety and feasibility of intraoperative microdialysis. Study eligibility includes adults (>18yo) undergoing a clinically indicated surgery for known or suspected glioma. All patients with available analyzed microdialysate samples as of 4/1/2021 ( $n=5$ patients; 15 catheters) were included in the analysis. No patients nor catheters were excluded.

\section{Intraoperative Microdialysis}

Each patient underwent intraoperative microdialysis using three M-dialysis 100kDA catheters and 107 variable rate microdialysis pumps under an investigational device exemption. Full details regarding patients, catheters, and perfusate are available in supplemental material. 
medRxiv preprint doi: https://doi.org/10.1101/2021.08.24.21262320; this version posted January 1, 2022. The copyright holder for this preprint (which was not certified by peer review) is the author/funder, who has granted medRxiv a license to display the preprint in perpetuity.

All rights reserved. No reuse allowed without permission.

Briefly, catheters were continuously perfused at $2 \mu \mathrm{L} / \mathrm{min}$ with isotonic perfusate containing $3 \%$ Dextran to balance oncotic pressure and maintain net fluid flux across the catheter membrane. Catheter target locations were selected by the surgeon to facilitate sampling of radiographically diverse regions. The intended catheter depth was marked on the catheter with sterile adhesive tape (Steri-Strip). After dural opening, but prior to tumor resection, a small pial opening was made at the intended catheter entry sites. Each pre-primed catheter was then advanced manually along pre-planned trajectories to the appropriate depth with the aid of computerguided neuro-navigation. Cortical surface mapping procedures were performed as needed after catheter implantation. Surgical resection then began, working initially away from the implanted catheters. Collection vials were initially changed after all catheters were in place and every 20 minutes thereafter to obtain multiple $40 \mu \mathrm{L}$ aliquots per catheter. Collection continued until at least two aliquots had been collected. Each aliquot was immediately labeled and placed directly on dry ice in the operating room. The second aliquot after catheter placement was submitted for metabolomic analysis to minimize potential confounders of variably equilibrated microdialysate in the first aliquot. Any additional aliquots, when available, were saved for future analysis. Catheters were removed prior to resection of the sampled region of brain or tumor. When possible, tissue samples approximately representative of the microdialysis-sampled regions were collected as separate specimens for pathology. When available, CSF was sampled from within the surgical field. With exception of intraoperative microdialysis, no other aspects of the surgical procedure, or post-operative care were altered. Extent of resection was guided in four cases by awake language and/or motor mapping and in all cases by imaging via computerguided neuro-navigation. 5-ALA fluorescence was additionally used to guide resection of enhancing lesions and intraoperative ultrasound was used to guide extent of non-enhancing lesions. Microdialysate aliquots were stored at $-80 \mathrm{C}$ until analyzed. Correlative clinical information, including medication timing and dose, were obtained from the medical record. No complications occurred that were attributable to use of intraoperative microdialysis. One patient (Astro ${ }^{4-m u t}$ ) with a large recurrent tumor had expected temporary post-operative exacerbation of baseline hemiparesis. Patient GBM $^{\mathrm{WT}} 1$ underwent a second surgery six months after the index operation for resection of a recurrent growing enhancing lesion; pathology demonstrated only pseudo-progression. Patient $\mathrm{GBM}^{\mathrm{WT}} 2$ underwent a repeat resection for a recurrent enhancing lesion nine months after the primary resection; pathology revealed recurrent IDH-WT GBM. As of manuscript submission, all patients remain alive ( $n=19.5$ months).

\section{Pathology and Molecular Tumor analysis}


medRxiv preprint doi: https://doi.org/10.1101/2021.08.24.21262320; this version posted January 1, 2022. The copyright holder for this preprint (which was not certified by peer review) is the author/funder, who has granted medRxiv a license to display the preprint in perpetuity.

All rights reserved. No reuse allowed without permission.

Tumor samples from each patient underwent standard histopathological analysis for diagnostic purposes. Immunohistochemical analysis for IDH R132H was used to determine IDH status. Negative cases were confirmed by IDH1/2 sequencing. GBMs were evaluated for MGMT methylation. TERT promotor mutations were identified by sequencing. $1 p / 19 q$ co-deletion, CDKN2A status, and karyotype complexity were evaluated via chromosomal microarray.

\section{Targeted Analysis of D/L-2-HG}

Targeted metabolomic analysis of microdialysate and CSF samples was performed by the Mayo Clinic metabolomic core facility. $L$ and $D$ isomers of 2-hydroxyglutaratic acid were separated and quantified by liquid chromatography mass spectrometry (LC/MS) using slight modifications to previously described methods ${ }^{37-39}$. Further details may be found in Supplemental Methods.

\section{Untargeted Metabolomic Analysis}

Untargeted metabolomic analysis was performed by Metabolon, Inc. Seventeen microdialysate samples were analyzed, including two blanks comprised perfusate that had passed through catheters $\mathrm{C}$ of patients $\mathrm{Oligo}^{3}$ and $\mathrm{GBM}^{\mathrm{WT}} 2$ during the flush cycle prior to collecting the first aliquot. Fifteen microdialysate samples comprised the second aliquot collected from each catheter (3 catheters in 15 patients) after intraoperative placement within the tissue. Following protein removal, four fractions of the metabolite extract were randomly run across the platform and analyzed by ultra-performance liquid chromatography tandem mass spectrometry (UPLC-MS/MS). Further details can be found in Supplemental Methods. One sample $\left(\mathrm{GBM}^{\mathrm{WT}}\right.$ 1: Catheter $\left.\mathrm{B}\right)$ was found by Metabolon to contain $<20 \mu \mathrm{L}$ and samples were run with a $50 \%$ dilution. As such, identified peak areas for metabolites in this sample were doubled prior to use in analysis. Otherwise, raw peak areas were used for relative quantitative analysis.

Of the 353 biochemicals detected in the microdialysate samples, 315 were assigned a named chemical identity by metabolon; 297 of which were present in at least half of the catheters and 181 of these were detected in all 15 samples. The 181 metabolites were used for clustering, correlation, and enrichment analyses. Full raw data are provided in supplemental materials.

\section{Statistical Analysis}


medRxiv preprint doi: https://doi.org/10.1101/2021.08.24.21262320; this version posted January 1, 2022. The copyright holder for this preprint (which was not certified by peer review) is the author/funder, who has granted medRxiv a license to display the preprint in perpetuity.

All rights reserved. No reuse allowed without permission.

Data are presented as raw or normalized peak areas provided from Metabolon Inc., where applicable, and are available in Supplemental File 1. MetaboAnalyst 5.0 was used for hierarchical clustering heat maps, machine learning algorithms (PCA, PLS-DA, sPLS-DA, OPLS-DA), and FC analyses. Data from Metabolon underwent normalization of peak areas by the median of the 10 least variant metabolites (as measured by coefficient of variance, $\mathrm{CV}=$ $\sigma / \mu$ ), for which there were no measurable peak areas within the two blank microdialysate samples. Enrichment Analysis was performed using GSEA 4.1.0 (Gene Set Enrichment Analysis), repurposed for metabolite set analysis using custom feature sets. Graphs were generated using GraphPad PRISM 9.1. FDR $<0.05$ was considered statistically significant for enrichment analysis. Further details of statistical analysis workflows are provided below.

\section{Ranked Metabolite and CSF lists}

Ranked metabolite lists of tumor (Catheter A or B) versus brain (Catheter $\mathrm{C}$ ) were generated in four patients (Astro ${ }^{4-m u t}, \mathrm{GBM}^{\mathrm{WT}} 1, \mathrm{GBM}^{\mathrm{WT}} 2$, and $\mathrm{Oligo}^{3}$ ) based on calculated fold changes of the raw peak area data $(\mathrm{A} / \mathrm{C}$ or $\mathrm{B} / \mathrm{C}$ for the metabolite). This could not be done for patient Oligo $^{2}$ given the lack of brain-sampling catheter. To determine an overall tumor-to-brain ranking for each metabolite, each patient's tumor-to-brain metabolites were ranked within the patient and then averaged across all four patients for that metabolite. The individual tumor-tobrain rankings were compared against this overall tumor-to-brain ranking associated with each metabolite. A $25 \%$ standard was generated based on the first quartile of a metabolite's raw peak areas across all 15 catheters. Ranked lists were generated for catheter A versus the $25 \%$ standard or versus that patient's own CSF, when applicable.

To compare catheter versus catheter to catheter versus $25 \%$ standard or versus CSF rankings, separate overall tumor-to-metabolite ranking lists were made which excluded the patient of interest, i.e. in patient Astro ${ }^{4-m u t}$, only patients $\mathrm{GBM}^{\mathrm{WT}} 1, \mathrm{GBM}^{\mathrm{WT}} 2$, and $\mathrm{Oligo}^{3} \mathrm{~A}$ versus $\mathrm{C}$ and $\mathrm{A}$ versus CSF were used to generate the overall tumor-to-brain ranking ("leave-one-out" analysis). The top 30 metabolites as calculated by this overall ranking were then extracted and the rankings for those 30 metabolites as determined by Catheter to Catheter, Catheter to $25 \%$ standard, or Catheter to CSF ranking were compared.

\section{Heatmaps}

To generate a heat map of the metabolites present in at least half of the catheters, metabolites were excluded, which were not present in $>n=8$ catheters. Tumor-to-brain rankings were calculated individually for four patients based on Catheter $A$ versus $C$ and ranked by fold 
medRxiv preprint doi: https://doi.org/10.1101/2021.08.24.21262320; this version posted January 1, 2022. The copyright holder for this preprint (which was not certified by peer review) is the author/funder, who has granted medRxiv a license to display the preprint in perpetuity.

All rights reserved. No reuse allowed without permission.

change from greatest abundance in tumor to least abundant. These rankings were then averaged across the four patients to yield the tumor-to-brain ranking of the 297 metabolites. The top 25 metabolites (tumor-metabolites) and the bottom 25 metabolites (brain metabolites) were extracted, and their normalized peak area values plotted for each catheter in the heat map. Class of metabolite was determined by a literature search.

\section{Enrichment Analysis}

Analysis of samples from individual patients may generate insufficient power to draw conclusions based on any single metabolite. However, untargeted metabolomic analysis of even two catheters can yield a ranked list of differentially abundant metabolites in one catheter versus the other. Gene Set Enrichment Analysis (GSEA) is the most widely utilized analytical method for rank-based analysis of data sets in biomedicine, developed for comparing gene expression data sets. Although a metabolite set enrichment analysis is available in MetaboAnalyst, GSEA provided generally more conservative enrichment estimates and more granular visualization together with analytical tools to help identify the most important metabolites driving enrichment. GSEA is frequently performed using curated gene sets from the molecular signatures database (MSigDB), though custom feature sets can be used enabling enrichment analysis of metabolites rather than metabolites. We created ranked metabolite lists for each of our 15 catheter samples by comparing them to other catheter samples for that same patient. When available, we also created ranked metabolites lists for each catheter versus the patient's CSF. The lists were ranked based on fold change. We also created over 350 metabolite libraries against which these ranked lists could be compared to determine relative positive and negative enrichment (Supplemental Data). These libraries were generated based on fold change, t-test values, and signal-to-noise ratio of both human and mouse metabolomic data from prior and ongoing studies. Additionally, results from Björkblom et al. were included as an external reference ${ }^{15}$. The number of feature sets evaluated is included in calculations to generate a normalized enrichment score and FDR for each.

The full ranked metabolite lists (.rnk) of catheter $A$ versus $C$ for patients with both tumor and brain $(n=4)$ and catheter $A$ versus CSF $(n=4)$ were used as the reference data against which to assess relative enrichment using the custom .gmx file. This .gmx file included the top 75 metabolites comparing catheters $A$ (enhancing) versus $C$ (brain) for each patient with astrocytomas (Astro ${ }^{4-m u t}, G B M^{W T} 1$, and $G B^{W T} 1$ ) and the patient with a grade 3 oligodendroglioma. This .gmx file also included the top 50 metabolites comparing catheter A 
medRxiv preprint doi: https://doi.org/10.1101/2021.08.24.21262320; this version posted January 1, 2022. The copyright holder for this preprint (which was not certified by peer review) is the author/funder, who has granted medRxiv a license to display the preprint in perpetuity. All rights reserved. No reuse allowed without permission.

(enhancing, $n=3$, or FLAIR, $n=1$ ) versus CSF for each patient with astrocytomas and the patient with a grade 2 oligodendroglioma.

\section{MetaboAnalyst}

Metabolomic analyses were performed using MetaboAnalyst (5.0), a publicly available web-based tool to analyze and visualize metabolomic data ${ }^{40}$. The normalized peak area data for the 181 metabolites present across all 15 samples was inputted into MetaboAnalyst without any further filtering.

\section{Supervised and Unsupervised Metabolomic Analyses}

Catheter samples were subdivided into groups based on IDH-status and patient identity. Given the desire to elucidate individualized $n=1$ tumor signatures by comparing catheters within individual patients, each catheter was analyzed as a unique sample with clustering analyses used to determine the relative importance of each variable. To ensure conservative analysis with minimal risk of introduced bias, comparisons were based on the full cohort of 181 metabolites quantifiable in all 15 microdialysis samples. No metabolites were filtered or excluded and no data interpolation steps were performed other than normalization by the median of the top 10 least-variable metabolites.

To evaluate apparent groupings within the data in an unbiased manner, we started with Principal Component Analysis (PCA)--an unsupervised machine learning algorithm that reduces the dimensionality of large data sets to highlight the most prominent patterns in a data set ${ }^{41}$. Following this, a supervised machine learning algorithm, sparse PLS-DA (sPLS-DA) was performed, which selects the most predictive variables between various groups ${ }^{42}$.

\section{Spearman Correlation}

Assuming a monotonical rather than linear relation between metabolites and samples, Spearman Correlation maps were generated in MetaboAnalyst based on features (metabolites present across all samples) and samples. Heat maps were generated using the correlation heat map package on MetaboAnalyst from the normalized data.

Acknowledgements: We would like to thank all of our patients who selflessly participated in this study, without whom this work and any advancement in the field of neuro-oncology would truly not be possible. 
medRxiv preprint doi: https://doi.org/10.1101/2021.08.24.21262320; this version posted January 1, 2022. The copyright holder for this preprint (which was not certified by peer review) is the author/funder, who has granted medRxiv a license to display the preprint in perpetuity. All rights reserved. No reuse allowed without permission.

\section{References}

1 Stupp, R. et al. Radiotherapy plus concomitant and adjuvant temozolomide for glioblastoma. N Engl J Med 352, 987-996, doi:10.1056/NEJMoa043330 (2005).

2 Yan, H. et al. IDH1 and IDH2 mutations in gliomas. N Engl J Med 360, 765-773, doi:10.1056/NEJMoa0808710 (2009).

3 SongTao, Q. et al. IDH mutations predict longer survival and response to temozolomide in secondary glioblastoma. Cancer Sci 103, 269-273, doi:10.1111/j.13497006.2011.02134.x (2012).

4 Shibao, S. et al. Metabolic heterogeneity and plasticity of glioma stem cells in a mouse glioblastoma model. Neuro Oncol 20, 343-354, doi:10.1093/neuonc/nox170 (2018).

5 Kondo, Y., Katsushima, K., Ohka, F., Natsume, A. \& Shinjo, K. Epigenetic dysregulation in glioma. Cancer Sci 105, 363-369, doi:10.1111/cas.12379 (2014).

6 Kathagen-Buhmann, A. et al. Glycolysis and the pentose phosphate pathway are differentially associated with the dichotomous regulation of glioblastoma cell migration versus proliferation. Neuro Oncol 18, 1219-1229, doi:10.1093/neuonc/now024 (2016).

7 Vlashi, E. et al. Metabolic state of glioma stem cells and nontumorigenic cells. Proc Natl Acad Sci U S A 108, 16062-16067, doi:10.1073/pnas.1106704108 (2011).

8 Strickland, M. \& Stoll, E. A. Metabolic Reprogramming in Glioma. Front Cell Dev Biol 5, 43, doi:10.3389/fcell.2017.00043 (2017).

9 Lynes, J. et al. Cytokine Microdialysis for Real-Time Immune Monitoring in Glioblastoma Patients Undergoing Checkpoint Blockade. Neurosurgery 84, 945-953, doi:10.1093/neuros/nyy392 (2019).

10 Portnow, J. et al. A pilot microdialysis study in brain tumor patients to assess changes in intracerebral cytokine levels after craniotomy and in response to treatment with a targeted anti-cancer agent. J Neurooncol 118, 169-177, doi:10.1007/s11060-014-1415-4 (2014).

11 Blakeley, J. O. et al. Effect of blood brain barrier permeability in recurrent high grade gliomas on the intratumoral pharmacokinetics of methotrexate: a microdialysis study. $J$ Neurooncol 91, 51-58, doi:10.1007/s11060-008-9678-2 (2009).

12 Joukhadar, C. \& Müller, M. Microdialysis: current applications in clinical pharmacokinetic studies and its potential role in the future. Clin Pharmacokinet 44, 895913, doi:10.2165/00003088-200544090-00002 (2005).

13 Ryals, J., Lawton, K., Stevens, D. \& Milburn, M. Metabolon, Inc. (2007).

14 Wibom, C. et al. Metabolomic patterns in glioblastoma and changes during radiotherapy: a clinical microdialysis study. J Proteome Res 9, 2909-2919, doi:10.1021/pr901088r (2010).

15 Bjorkblom, B. et al. Metabolic response patterns in brain microdialysis fluids and serum during interstitial cisplatin treatment of high-grade glioma. Br J Cancer 122, 221-232, doi:10.1038/s41416-019-0652-x (2020).

16 Xiong, N. et al. Using arterial-venous analysis to characterize cancer metabolic consumption in patients. Nat Commun 11, 3169, doi:10.1038/s41467-020-16810-8 (2020). 
medRxiv preprint doi: https://doi.org/10.1101/2021.08.24.21262320; this version posted January 1, 2022. The copyright holder for this preprint (which was not certified by peer review) is the author/funder, who has granted medRxiv a license to display the preprint in perpetuity. All rights reserved. No reuse allowed without permission.

$17 \mathrm{Bi}, \mathrm{J}$. et al. Altered cellular metabolism in gliomas - an emerging landscape of actionable co-dependency targets. Nature Reviews Cancer 20, 57-70, doi:10.1038/s41568-019-0226-5 (2020).

18 Zhang, Y. et al. Elevated signature of a gene module coexpressed with CDC20 marks genomic instability in glioma. Proceedings of the National Academy of Sciences 116, 6975-6984, doi:10.1073/pnas.1814060116 (2019).

19 Milinkovic, V. et al. Genomic instability and p53 alterations in patients with malignant glioma. Exp Mol Pathol 93, 200-206, doi:10.1016/j.yexmp.2012.05.010 (2012).

20 Huang, H. et al. Suppression of mitochondrial ROS by prohibitin drives glioblastoma progression and therapeutic resistance. Nature Communications 12, 3720, doi:10.1038/s41467-021-24108-6 (2021).

21 Steinbach, J. P., Wolburg, H., Klumpp, A., Probst, H. \& Weller, M. Hypoxia-induced cell death in human malignant glioma cells: energy deprivation promotes decoupling of mitochondrial cytochrome c release from caspase processing and necrotic cell death. Cell Death \& Differentiation 10, 823-832, doi:10.1038/sj.cdd.4401252 (2003).

22 Tanaka, K. et al. Glioma cells require one-carbon metabolism to survive glutamine starvation. Acta Neuropathologica Communications 9, 16, doi:10.1186/s40478-02001114-1 (2021).

23 Mondal, S., Bhattacharya, K. \& Mandal, C. Nutritional stress reprograms dedifferention in glioblastoma multiforme driven by PTEN/Wnt/Hedgehog axis: a stochastic model of cancer stem cells. Cell Death Discovery 4, 110, doi:10.1038/s41420-018-0126-6 (2018).

24 Locasale, J. W. et al. Metabolomics of human cerebrospinal fluid identifies signatures of malignant glioma. Mol Cell Proteomics 11, M111.014688, doi:10.1074/mcp.M111.014688 (2012).

25 Ballester, L. Y. et al. Analysis of cerebrospinal fluid metabolites in patients with primary or metastatic central nervous system tumors. Acta Neuropathologica Communications 6, 85, doi:10.1186/s40478-018-0588-z (2018).

26 Konteatis, Z. et al. Vorasidenib (AG-881): A First-in-Class, Brain-Penetrant Dual Inhibitor of Mutant IDH1 and 2 for Treatment of Glioma. ACS Med Chem Lett 11, 101-107, doi:10.1021/acsmedchemlett.9b00509 (2020).

27 Molloy, A. R. et al. MR-detectable metabolic biomarkers of response to mutant IDH inhibition in low-grade glioma. Theranostics 10, 8757-8770, doi:10.7150/thno.47317 (2020).

28 Andronesi, O. C. et al. Pharmacodynamics of mutant-IDH1 inhibitors in glioma patients probed by in vivo 3D MRS imaging of 2-hydroxyglutarate. Nat Commun 9, 1474, doi:10.1038/s41467-018-03905-6 (2018).

29 Wenger, K. J. et al. Non-Invasive Measurement of Drug and 2-HG Signals Using (19)F and (1)H MR Spectroscopy in Brain Tumors Treated with the Mutant IDH1 Inhibitor BAY1436032. Cancers (Basel) 12, doi:10.3390/cancers12113175 (2020).

30 Panosyan, E. H. et al. Asparagine depletion potentiates the cytotoxic effect of chemotherapy against brain tumors. Mol Cancer Res 12, 694-702, doi:10.1158/15417786.Mcr-13-0576 (2014).

31 Yamashita, D. et al. Targeting glioma-initiating cells via the tyrosine metabolic pathway. J Neurosurg 134, 721-732, doi:10.3171/2019.11.Jns192028 (2020). 
medRxiv preprint doi: https://doi.org/10.1101/2021.08.24.21262320; this version posted January 1, 2022. The copyright holder for this preprint (which was not certified by peer review) is the author/funder, who has granted medRxiv a license to display the preprint in perpetuity. All rights reserved. No reuse allowed without permission.

32 Friedrich, M. et al. Tryptophan metabolism drives dynamic immunosuppressive myeloid states in IDH-mutant gliomas. Nature Cancer 2, 723-740, doi:10.1038/s43018-02100201-z (2021).

33 Vettore, L., Westbrook, R. L. \& Tennant, D. A. New aspects of amino acid metabolism in cancer. British Journal of Cancer 122, 150-156, doi:10.1038/s41416-019-0620-5 (2020).

34 Fink, M. A. et al. L-Carnitine-Mediated Tumor Cell Protection and Poor Patient Survival Associated with OCTN2 Overexpression in Glioblastoma Multiforme. Clin Cancer Res 25, 2874-2886, doi:10.1158/1078-0432.Ccr-18-2380 (2019).

35 Juraszek, B., Czarnecka-Herok, J. \& Nałęcz, K. A. Glioma cells survival depends both on fatty acid oxidation and on functional carnitine transport by SLC22A5. Journal of Neurochemistry 156, 642-657, doi:https://doi.org/10.1111/inc.15124 (2021).

36 Gordon, N. Guanidinoacetate methyltransferase deficiency (GAMT). Brain Dev 32, 79-81, doi:10.1016/j.braindev.2009.01.008 (2010).

37 Oldham, W. M. \& Loscalzo, J. Quantification of 2-Hydroxyglutarate Enantiomers by Liquid Chromatography-mass Spectrometry. Bio Protoc 6, doi:10.21769/BioProtoc.1908 (2016).

38 Struys, E. A., Jansen, E. E., Verhoeven, N. M. \& Jakobs, C. Measurement of urinary D- and L-2-hydroxyglutarate enantiomers by stable-isotope-dilution liquid chromatographytandem mass spectrometry after derivatization with diacetyl-L-tartaric anhydride. Clin Chem 50, 1391-1395, doi:10.1373/clinchem.2004.033399 (2004).

39 Cheng, Q. Y. et al. Sensitive Determination of Onco-metabolites of D- and L-2hydroxyglutarate Enantiomers by Chiral Derivatization Combined with Liquid Chromatography/Mass Spectrometry Analysis. Sci Rep 5, 15217, doi:10.1038/srep15217 (2015).

40 Pang, Z. et al. MetaboAnalyst 5.0: narrowing the gap between raw spectra and functional insights. Nucleic Acids Res 49, W388-w396, doi:10.1093/nar/gkab382 (2021).

41 Wold, S., Esbensen, K. \& Geladi, P. Principal component analysis. Chemometrics and intelligent laboratory systems 2, 37-52 (1987).

42 Chung, D. \& Keles, S. Sparse partial least squares classification for high dimensional data. Stat Appl Genet Mol Biol 9, Article17, doi:10.2202/1544-6115.1492 (2010). 
medRxiv preprint doi: https://doi.org/10.1101/2021.08.24.21262320; this version posted January 1, 2022. The copyright holder for this preprint (which was not certified by peer review) is the author/funder, who has granted medRxiv a license to display the preprint in perpetuity.

Figure 1. Patient characteristics, intraoperative microdialysis set-up, planning, and D-2Hydroxyglutarate

(A) The patient IDs and final pathologic diagnoses, including IDH-status and other available key molecular features, are summarized together with the catheter locations and availability of CSF from the operative field. Additional specifics regarding each patient, tumor, and catheter are available in Supplemental Table 1. *Diagnosis of IDH-WT GBM was reached for patient $\mathrm{GBM}^{\mathrm{WT}} 2$ without need for further molecular studies.

(B) A representative intraoperative photograph $\left(\mathrm{Oligo}^{2}\right)$ demonstrating the experimental setup, including placement of three $100 \mathrm{kDA}$ microdialysis catheters, as well as pumps and collection vials within the surgical field.

(C) Illustrative intraoperative trajectory views captured from the Neuronavigation system demonstrate the planned trajectory (blue line) toward the intended target location for each 10 $\mathrm{mm}$ microdialysis membrane (yellow box). The patient shown (Astro-mut) underwent catheter within enhancing (Catheter $A$ ) and non-enhancing tumor (Catheter $B$ ), in addition to relatively normal brain adjacent to tumor (Catheter $\mathrm{C}$ ).

(D) D-2-hydroxyglutarate (D-2-HG) concentration, as quantified via targeted metabolomics (LCMS), is shown for microdialysate from each of the 15 catheters. Patient IDH status is indicated as mutant (blue) or wild type (red). Symbol shape indicates catheter placement location (see legend). CSF from the surgical field was analyzed via targeted LC-MS in three patients and is shown where available (green X).

(E) Untargeted metabolomic analysis was performed on $20 \mu \mathrm{L}$ of microdialysate from the same aliquot as used for targeted metabolomics. 2-HG peak areas obtained via untargeted metabolomic analysis do not discriminate between D2- and L2-HG. These were correlated to the total of D-and-L-2-HG measured via targeted LC-MS. 
medRxiv preprint doi: https://doi.org/10.1101/2021.08.24.21262320; this version posted January 1, 2022. The copyright holder for this preprint (which was not certified by peer review) is the author/funder, who has granted medRxiv a license to display the preprint in perpetuity.

All rights reserved. No reuse allowed without permission.

A

\begin{tabular}{|c|c|c|c|c|c|c|c|}
\hline $\begin{array}{l}\text { Patient } \\
\text { ID }\end{array}$ & Pathology & $\begin{array}{l}\text { IDH } \\
\text { Status }\end{array}$ & Other molecular/genetic features & $\begin{array}{c}\text { Catheter } \\
\text { A }\end{array}$ & $\begin{array}{l}\text { Catheter } \\
\text { B }\end{array}$ & $\begin{array}{l}\text { Catheter } \\
\text { C }\end{array}$ & CSF \\
\hline Oligo $^{2}$ & $\begin{array}{l}\text { Oligodendroglioma } \\
\text { WHO } 2\end{array}$ & Mutant & 1p/19q co-deletion; TERT-mutant & $\begin{array}{l}\text { FLAIR } \\
\text { (F) }\end{array}$ & $\begin{array}{l}\text { FLAIR } \\
\text { (F) }\end{array}$ & $\begin{array}{l}\text { FLAIR } \\
\text { (F) }\end{array}$ & $Y$ \\
\hline Oligo $^{3}$ & $\begin{array}{l}\text { Oligodendroglioma } \\
\qquad \mathrm{WHO}_{3}\end{array}$ & Mutant & 1p/19q co-deletion; TERT-mutant & $\begin{array}{l}\text { FLAIR } \\
\text { (F) }\end{array}$ & $\begin{array}{l}\text { FLAIR } \\
\text { (F) }\end{array}$ & $\begin{array}{l}\text { FLAIR-Brain } \\
\text { (F-B or F*) }\end{array}$ & $\mathrm{N}$ \\
\hline Astro ${ }^{4-m u t}$ & $\begin{array}{c}\text { Astrocytoma } \\
\text { WHO } 4 \\
\text { (Recurrent) }\end{array}$ & Mutant & $\begin{array}{l}\text { MGMT non-methylated; loss of } \\
\text { CDKN2A/B; complex karyotype }\end{array}$ & $\begin{array}{l}\text { Enhancing } \\
\text { (E) }\end{array}$ & $\begin{array}{l}\text { FLAIR } \\
\text { (F) }\end{array}$ & $\begin{array}{c}\text { Brain } \\
\text { (B) }\end{array}$ & $Y$ \\
\hline $\mathrm{GBM}^{\mathrm{WT}} \mathbf{1}$ & Glioblastoma & $\begin{array}{l}\text { Wild- } \\
\text { type }\end{array}$ & $\begin{array}{l}\text { MGMT non-methylated; loss of } \\
\text { CDKN2A/B }\end{array}$ & $\begin{array}{l}\text { Enhancing } \\
\text { (E) }\end{array}$ & $\begin{array}{l}\text { FLAIR } \\
\text { (F) }\end{array}$ & $\begin{array}{c}\text { Brain } \\
\text { (B) }\end{array}$ & $Y$ \\
\hline GBM $^{\text {WT }} 2$ & Glioblastoma & $\begin{array}{l}\text { Wild- } \\
\text { type }\end{array}$ & Indeterminate MGMT methylation* & $\begin{array}{l}\text { Enhancing } \\
\text { (E) }\end{array}$ & $\begin{array}{l}\text { FLAIR } \\
\text { (F) }\end{array}$ & $\begin{array}{c}\text { Brain } \\
\text { (B) }\end{array}$ & $\mathrm{Y}$ \\
\hline
\end{tabular}

B

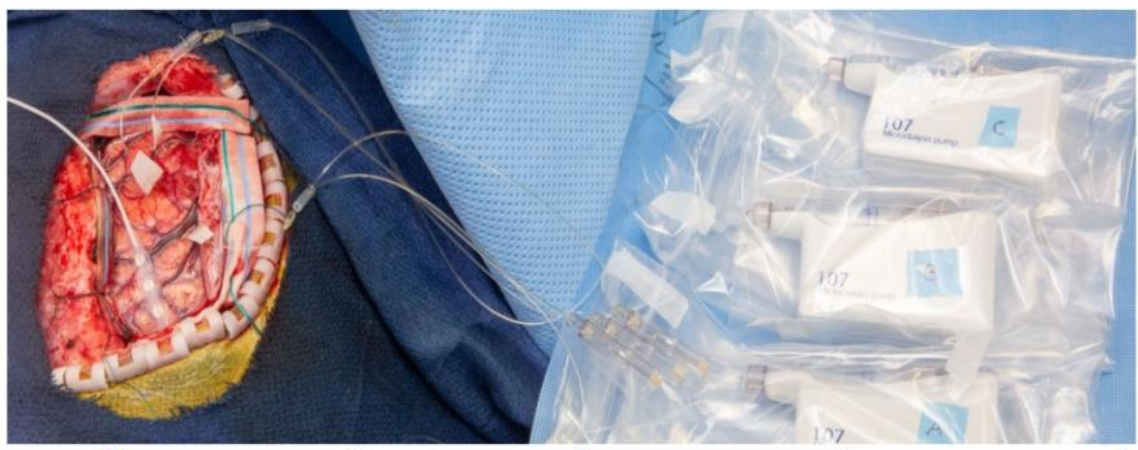

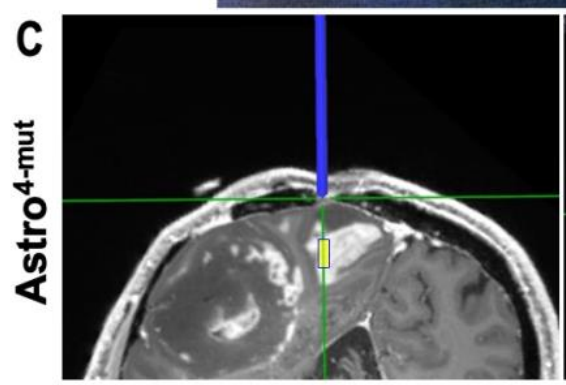

Catheter A: Enhancing

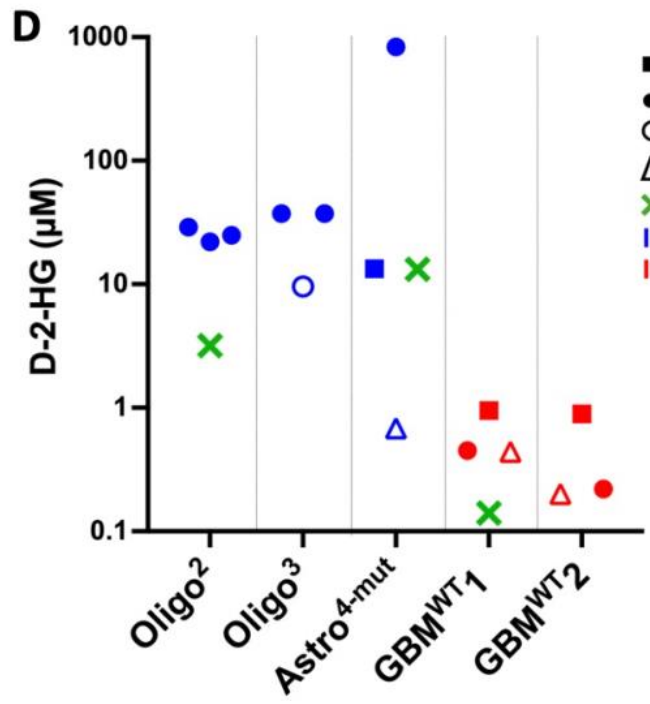

Catheter B: FLAIR

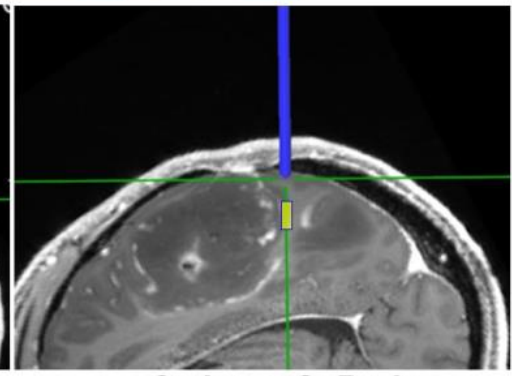

Catheter C: Brain

- Enhancing

- FLAIR

O FLAIR-Brain

$\triangle$ Brain

XCSF

IDH1-R132H

IDH-WT

E




medRxiv preprint doi: https://doi.org/10.1101/2021.08.24.21262320; this version posted January 1, 2022. The copyright holder for this preprint (which was not certified by peer review) is the author/funder, who has granted medRxiv a license to display the preprint in perpetuity. All rights reserved. No reuse allowed without permission.

Figure 2. Tumor and brain microdialysates have distinct metabolites.

(A) Untargeted metabolomic analysis yielded 181 named metabolites detected in microdialysate from all 15 catheters. Metabolites were ranked according to their fold change in tumor versus brain in each patient. For each patient, the rank order of each metabolite in each 2-catheter tumor/brain comparison (e.g., catheter A versus $C$ ) is conveyed as a heat map from 1 (orange, tumor) to 181 (green, brain). Metabolites are listed based on the average of ranks across enhancing tumor versus brain in three patients, Astro ${ }^{4-m u t}, G^{B W}{ }^{W T} 1$ and $G^{2} M^{W T} 2$. The top 10 tumor- and brain-associated metabolites are specified, in addition to the tumor/brain (cath A versus $\mathrm{C}$ ) fold change (orange and green boxed inset tables). The proportion of metabolic pathways as annotated by Metabolon present in the top 20 tumor and brain metabolites are depicted by pie graphs (orange: tumor-associated pathway, green: brain-associated pathway, blue: not specific to tumor or brain).

(B) Scatter plots demonstrating the relationship between fold change and rank in catheters $A$ versus $\mathrm{C}$ across the 181 consistently detected metabolites for patients Astro ${ }^{4-m u t}, \mathrm{GBM}^{\mathrm{WT}} 1$, $\mathrm{GBM}^{\mathrm{WT}} 2$, and Oligo $^{3}$.

(C) Scatter plots demonstrating the relationship between fold change and rank in catheters $B$ versus $C$ across the 181 consistently detected metabolites for patients Astro ${ }^{4-m u t}, G B M^{W T} 1$, $\mathrm{GBM}^{\mathrm{WT}} 2$, and Oligo $^{3}$.

2-O-MA: 2-O-methylascorbic acid; 3-M-His: 3-methylhistidine; Ara. acid: Arabinonic acid; AA Betaine: Aminovaleric acid betaine; Asp. acid: aspartic acid; DMTPA: 2,3-dihydroxy-5methylthio-4-pentenoic acid; Ery. Acid: erythronic acid; N(6)-M-Lysine: N(6)-Methyllysine; NAA: $\mathrm{N}$-acetyl-L-aspartic acid; NAAG: N-acetylaspartylglutamic acid; NANA: N-acetylneuraminic acid; Rib. acid: ribonic acid. 
medRxiv preprint doi: https://doi.org/10.1101/2021.08.24.21262320; this version posted January 1, 2022. The copyright holder for this preprint (which was not certified by peer review) is the author/funder, who has granted medRxiv a license to display the preprint in perpetuity.

All rights reserved. No reuse allowed without permission.

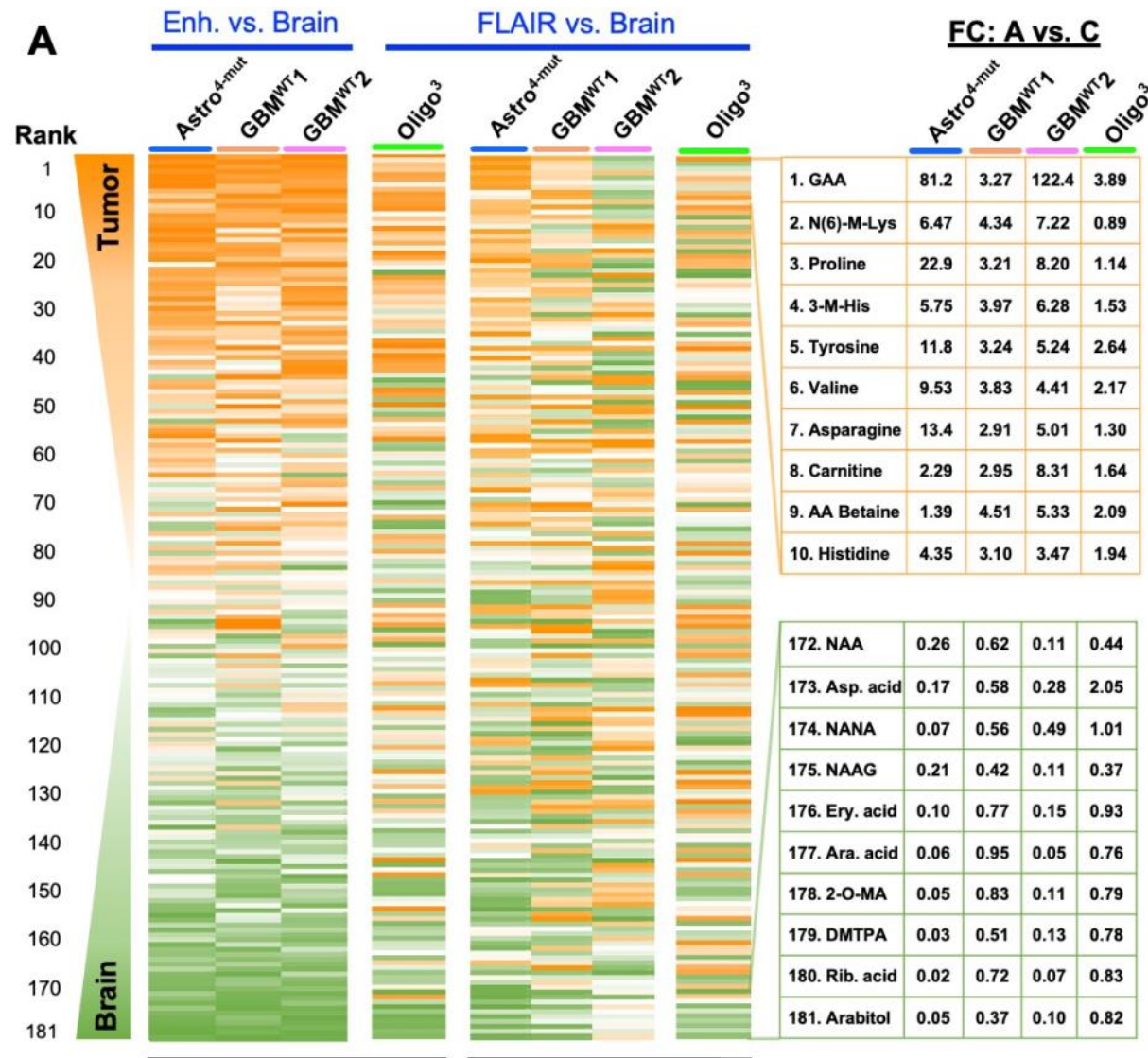

A vs. C

B

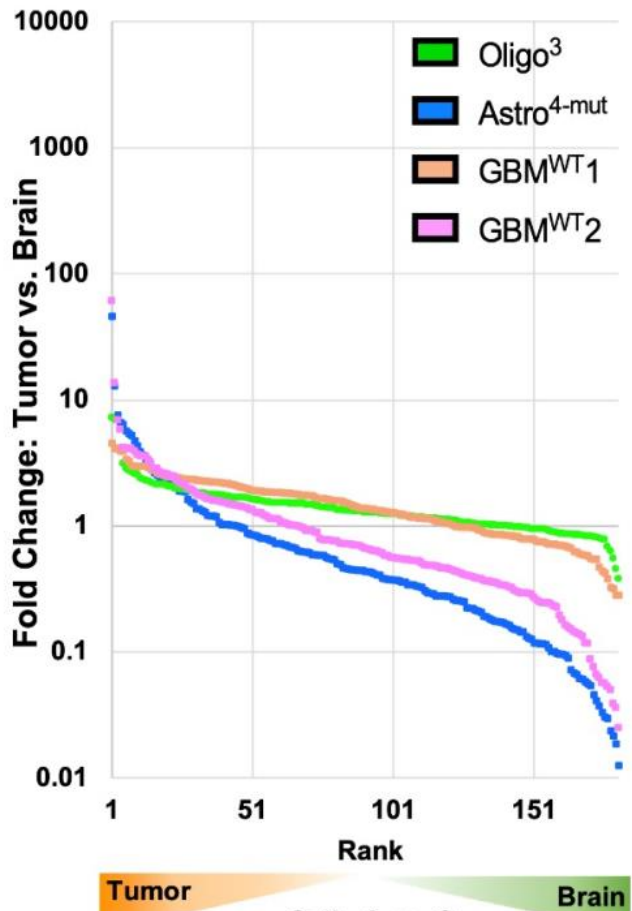

Cath. A vs. C
B vs. C

\section{C}

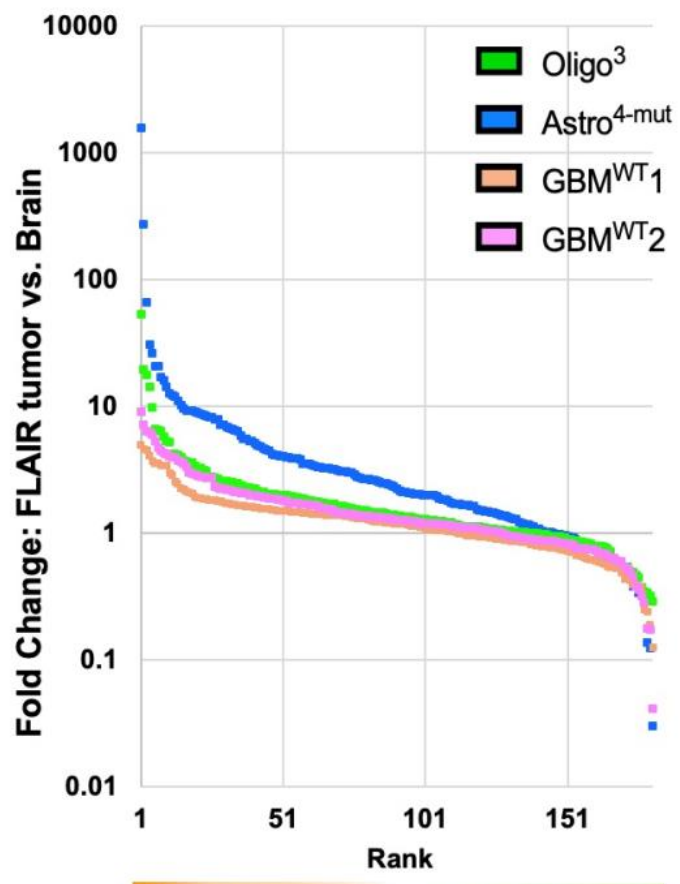

Tumor Cath. B vs. C Brain 
medRxiv preprint doi: https://doi.org/10.1101/2021.08.24.21262320; this version posted January 1, 2022. The copyright holder for this preprint (which was not certified by peer review) is the author/funder, who has granted medRxiv a license to display the preprint in perpetuity. All rights reserved. No reuse allowed without permission.

Figure 3. Reproducible individualized tumor versus brain microdialysate signature. (A) The fold change (tumor versus brain) of significantly differentially abundant metabolites as reported by Björkblom et al, 2020 were compared to the fold changes observed between tumor and brain in our current data set. Fold change values are color coded from $\leq 0.2$ (green = brain) to $\geq 8$ (orange = tumor). 2-H-3-MBA: 2-hydroxy-3-methylbutyric acid; 3-A-2-P: 3-amino-2piperidone; NAA: N-acetyl-L-aspartic acid.

(B) Metabolites were ranked by fold change between catheter $A$ versus $C$ (tumor versus brain) in each patient. The top 50 tumor- and brain-associated metabolites for each patient were used for enrichment analysis. A representative example enrichment analysis plot is shown demonstrating positive enrichment for the top 50 metabolites in GBM ${ }^{\mathrm{WT}} 1$ tumor in the ranked metabolite list of Oligo $^{3}$ tumor versus brain.

(C) A representative example enrichment analysis plot demonstrates negative enrichment for the top 50 brain-associated metabolites present in $\mathrm{GBM}^{\mathrm{WT}} 1$ brain in the ranked metabolite list of Oligo $^{3}$ tumor versus brain.

(D) Normalized enrichment scores (NES) and the associated false discovery rates (FDR) are shown based upon enrichment for the top 50 tumor- and brain-associated metabolites in the ranked metabolite lists (Catheter $A$ versus Catheter $\mathrm{C}$ ) for each patient. Enrichment for tumor metabolites identified in Björkblom et al., 2020 was also calculated to assess performance of the metabolite set enrichment strategy using an independent external tumor versus brain metabolite set. Values in bold indicate significant enrichment at $\mathrm{FDR}<0.05$. 
medRxiv preprint doi: https://doi.org/10.1101/2021.08.24.21262320; this version posted January 1, 2022. The copyright holder for this preprint (which was not certified by peer review) is the author/funder, who has granted medRxiv a license to display the preprint in perpetuity.

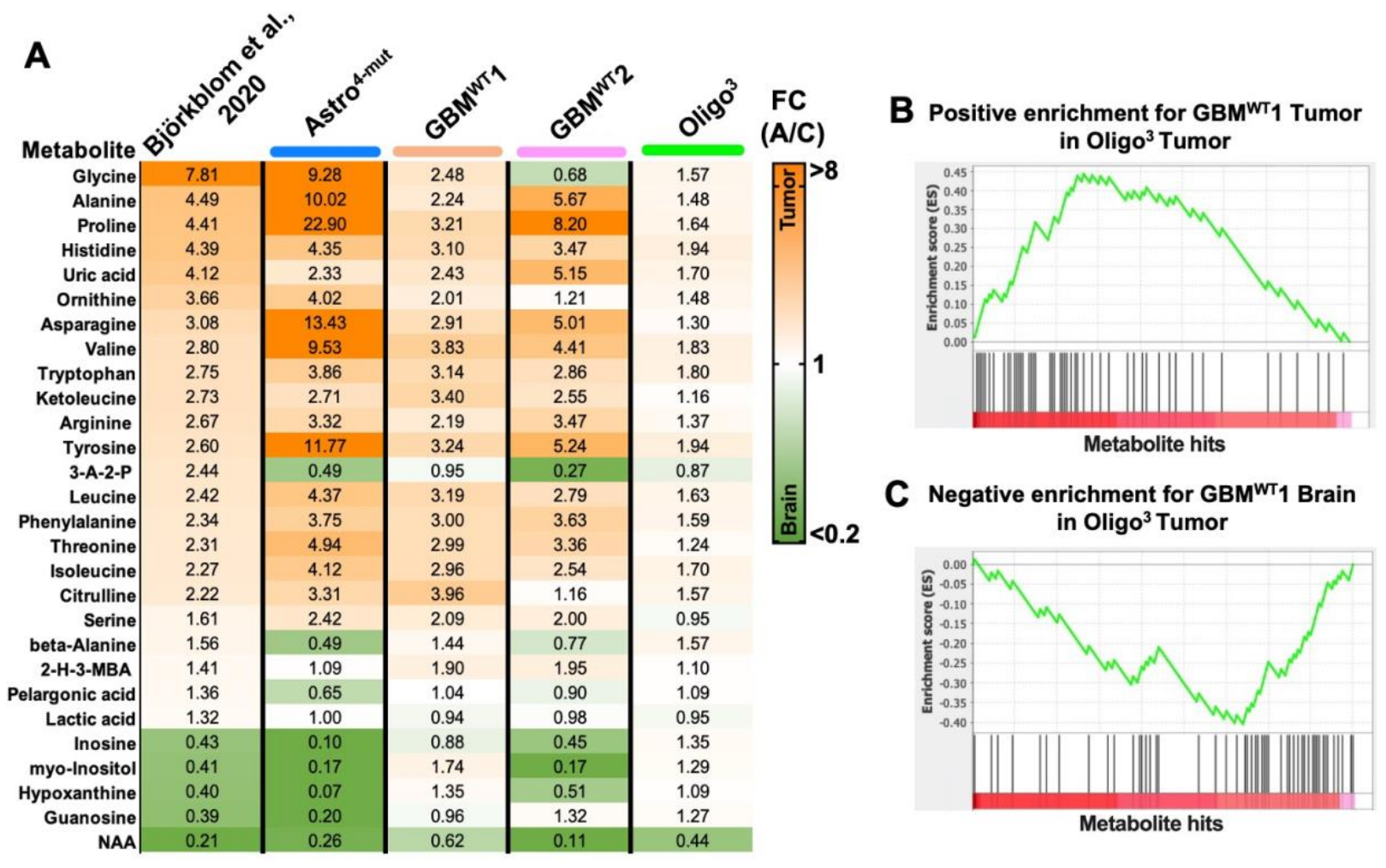

Catheter A vs. Catheter C

\begin{tabular}{|c|c|c|c|c|c|c|c|c|c|c|}
\hline & NES & $p^{5 x}$ & $\mathrm{C}^{80}$ & $0^{85}$ & $00^{30}$ & Metabolite set & & c & $0^{8}$ & o" \\
\hline \multirow{4}{*}{5} & \multirow{4}{*}{\begin{tabular}{|l|} 
혀 \\
$\underline{\Xi}$ \\
\multirow{2}{*}{} \\
\end{tabular}} & 7.20 & 3.72 & 3.90 & 2.48 & $\begin{array}{l}\text { Astro } 4 \text {-mut } \\
\text { Enhancing }\end{array}$ & 0 & 0 & 0 & 0 \\
\hline & & 2.94 & 7.25 & 2.91 & 3.21 & $\begin{array}{c}\text { GBMWT1 } \\
\text { Enhancing }\end{array}$ & 0 & 0 & 0 & 0 \\
\hline & & 4.05 & 3.63 & 7.25 & 2.79 & $\begin{array}{c}\text { GBMWT2 } \\
\text { Enhancing }\end{array}$ & 0 & 0 & 0 & 0 \\
\hline & & 1.76 & 3.46 & 2.64 & 7.19 & $\begin{array}{l}\text { Oligo }^{3} \\
\text { FLAIR }\end{array}$ & 0.037 & 0 & 0 & 0 \\
\hline \multirow[t]{3}{*}{0} & & -7.25 & -3.00 & -3.28 & -2.17 & $\begin{array}{l}\text { Astro 4-mut } \\
\text { Brain }\end{array}$ & 0 & 0 & 0 & 0.005 \\
\hline & \multirow{4}{*}{ 镸 } & -3.52 & -7.26 & -3.84 & -2.94 & $\begin{array}{c}\text { GBMWT1 } \\
\text { Brain }\end{array}$ & 0 & 0 & 0 & 0 \\
\hline & & -3.60 & -3.01 & -7.10 & -2.32 & $\begin{array}{c}\text { GBMWT2 } \\
\text { Brain }\end{array}$ & 0 & 0 & 0 & 0.002 \\
\hline \multirow[t]{2}{*}{-5} & & -2.68 & -2.64 & -2.45 & -6.99 & $\begin{array}{l}\text { Oligo }^{3} \\
\text { Brain }^{2}\end{array}$ & 0 & 0 & 0.001 & 0 \\
\hline & & 3.81 & 2.22 & 2.20 & 1.86 & $\begin{array}{c}\text { Tumor } \\
\text { (Björkblom, 2020) }\end{array}$ & 0 & 0.003 & 0.003 & 0.018 \\
\hline
\end{tabular}


medRxiv preprint doi: https://doi.org/10.1101/2021.08.24.21262320; this version posted January 1, 2022. The copyright holder for this preprint (which was not certified by peer review) is the author/funder, who has granted medRxiv a license to display the preprint in perpetuity.

All rights reserved. No reuse allowed without permission.

Figure 4. Use of a $25 \%$ reference and intraoperatively collected CSF can reproduce some, but not all, of the tumor versus brain microdialysate signature.

A) A $25^{\text {th }}$ percentile (25\%) reference standard was calculated for each of the 181 consistently detected metabolites (see methods). Metabolites were then ranked by fold change between abundance in each catheter versus the $25 \%$ reference standard. The top 50 catheter-versus $25 \%$ reference metabolites were then utilized as metabolite sets for enrichment analysis. Enrichment for these metabolite sets was evaluated within the ranked metabolite lists for enhancing (Astro ${ }^{4-m u t}, \mathrm{GBM}^{\mathrm{WT}}$ 1, and $\mathrm{GBM}^{\mathrm{WT}} 2$ ) or FLAIR-positive (Oligo ${ }^{3}$ ) tumor versus brain. NES and FDR values are reported for enrichment analyses within and between patients. (B) CSF from the same patient (when available) was utilized in place of a $25 \%$ reference. A similar method was used for $(A)$, but rather than comparing to a $25 \%$ reference, the metabolites were ranked by fold difference between abundance in the tumor microdialysate versus the CSF of that patient when available $(n=4)$. Values in bold for both $(A)$ and $(B)$ indicate significant enrichment at FDR<0.05.

(C)For each patient, a consensus "peer review" analysis was performed. For each patient, we determined a consensus ranked metabolite list for tumor versus brain leveraging data from each other available patient. Each patient's data was specifically excluded from the consensus metabolite used for its peer-review analysis. We then utilized each of the three available analysis strategies: catheter vs. catheter (purple; see also Fig 3D), catheter vs. 25\% standard (black; see also figure 4A), and catheter vs. CSF (blue; see also Fig 4B) to determine where the top 30 metabolites from each analysis fell on the consensus peer review rank. Results of all three analyses are shown for Astro ${ }^{4-m u t}, G B M^{W T} 1$, and $G B^{W T} 2$. No CSF was available for Oligo $^{3}$ and no non-tumor catheter was available to meaningfully perform Cath-Cath analysis for Oligo $^{2}$. 
A

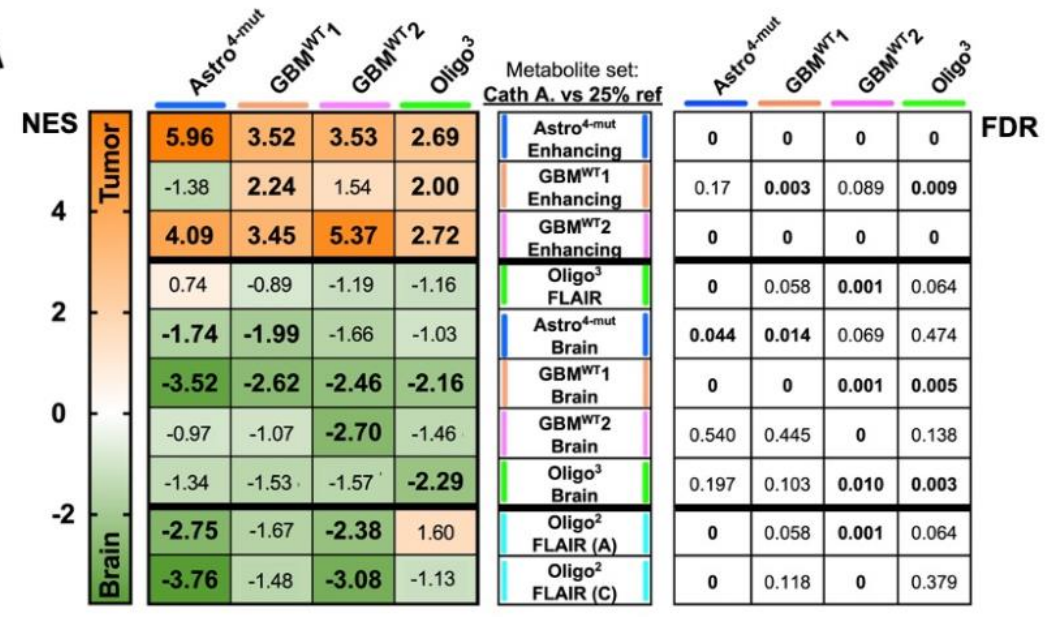

B

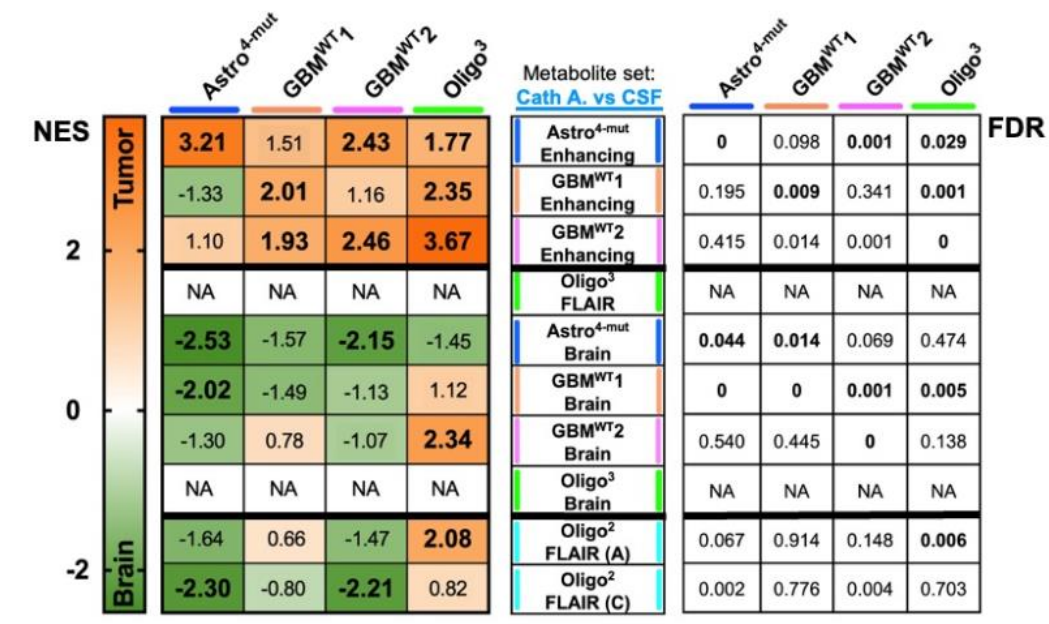

C

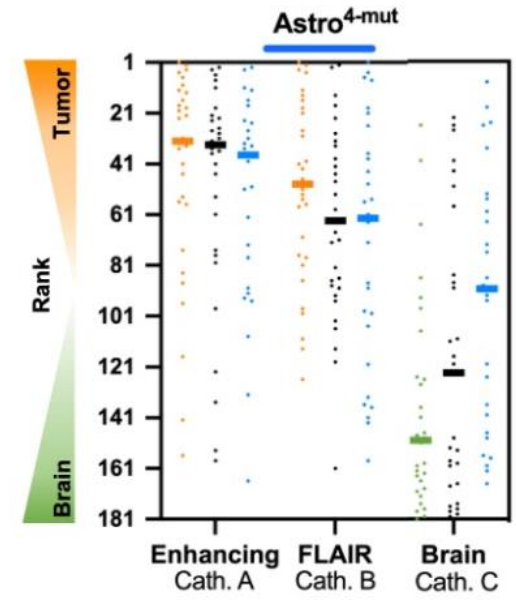

GBM $^{W_{1}}$

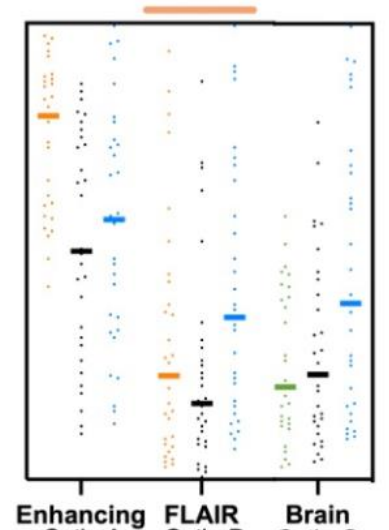

$\begin{array}{ccc}\text { Enhancing } & \text { FLAIR } & \text { Brain } \\ \text { Cath. A } & \text { Cath. B } & \text { Cath. C }\end{array}$

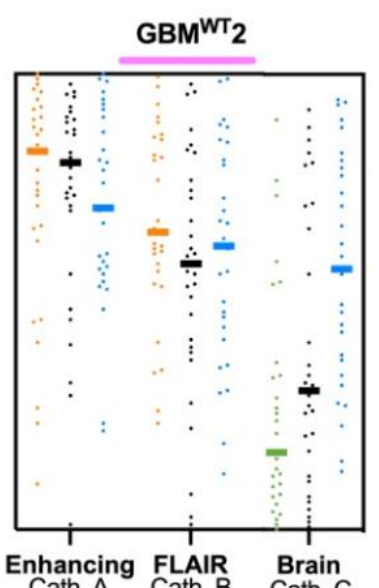

Enhancing FLAIR Brain

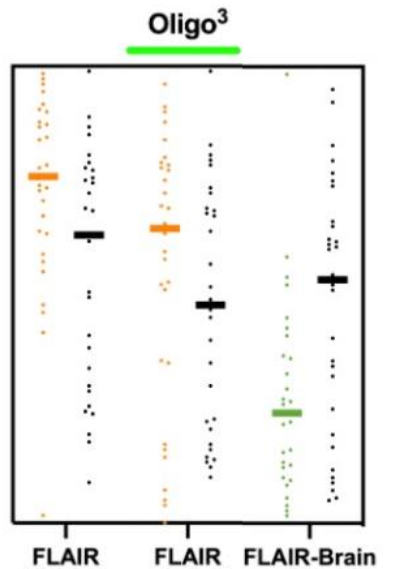

FLAIR FLAIR FLAIR-Brain

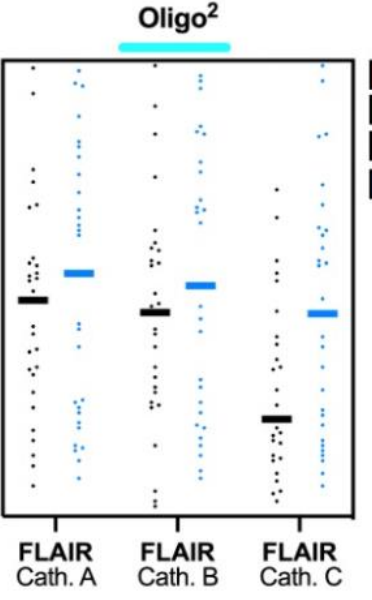

vs. Brain (Cath. c)

vs. Tumor (Cath. A)

vs. $25 \%$ reference

vs. Patient's cSF

Cath. A Cath. B Cath. C 
medRxiv preprint doi: https://doi.org/10.1101/2021.08.24.21262320; this version posted January 1, 2022. The copyright holder for this preprint (which was not certified by peer review) is the author/funder, who has granted medRxiv a license to display the preprint in perpetuity.

All rights reserved. No reuse allowed without permission.

Figure 5. Intraoperatively administered drugs in the microdialysate.

Untargeted metabolic data yielded (A) raw peaks areas for levetiracetam (Keppra), a highly blood-brain-barrier permeant drug. Peak areas were normalized by the median of the 10 least variant metabolites across all catheters, as determined by coefficient of variance in (B) levetiracetam, (C) cefazolin, (D) mannitol, (E) acetaminophen, and (F) caffeine. Dosages are listed for each patient. Additional information regarding dosages is available in Supplemental Table 2. ${ }^{*}=$ FLAIR-brain. 


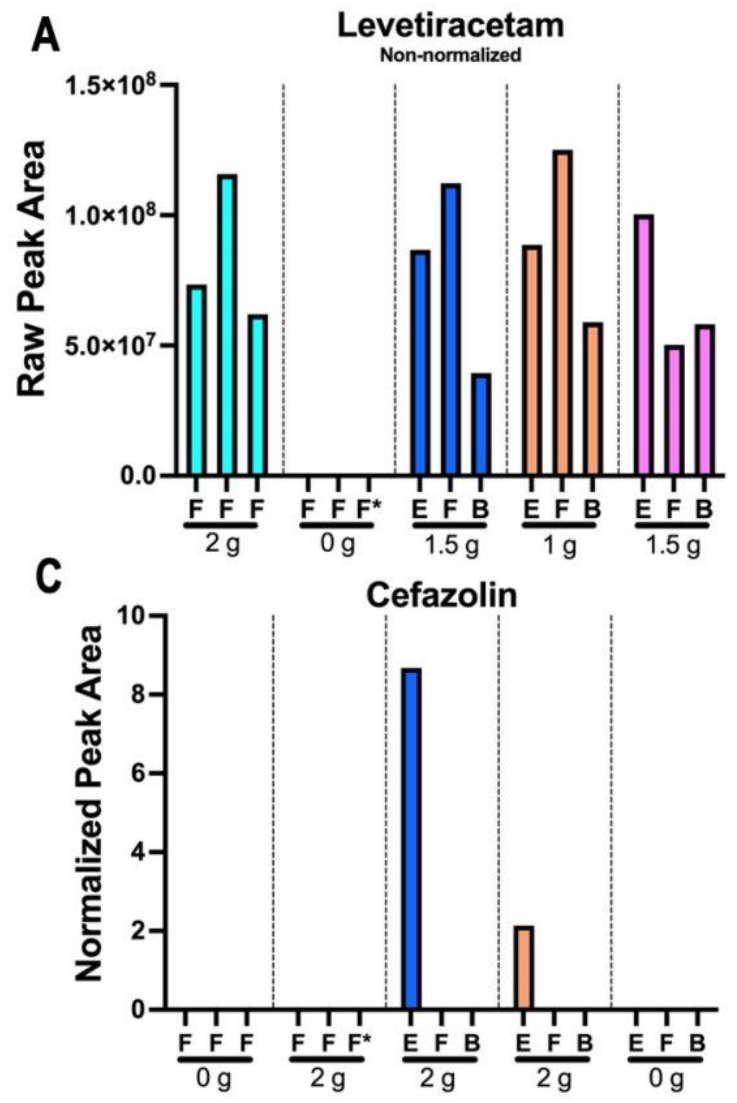

B

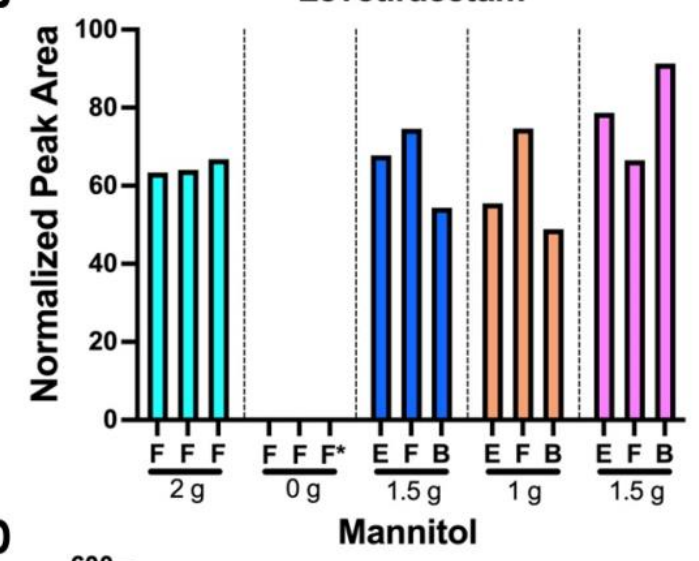

E

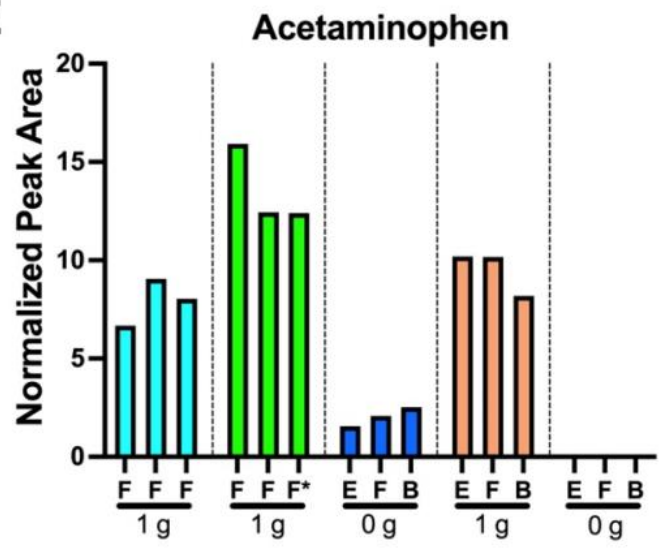

\section{Legend}

$\square$ Oligo $^{2}$

$\square$ Oligo $^{3}$

$\square$ Astro $^{4-m u t}$

$\square$ GBM $^{W T} 1$

口 $\mathrm{GBM}^{\mathrm{WT}} 2$

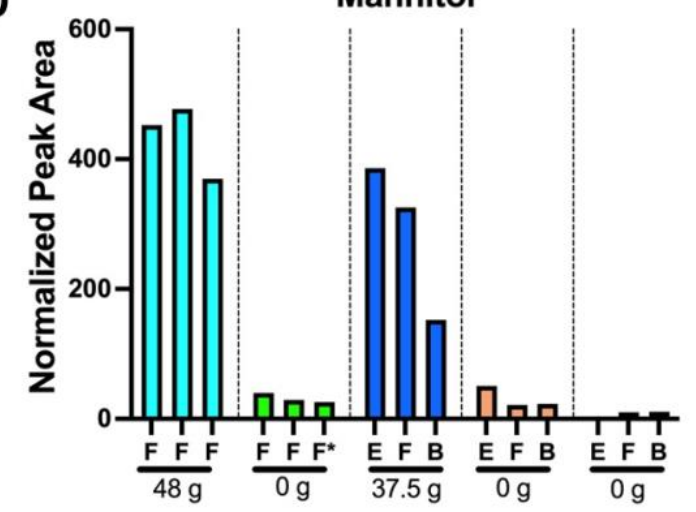

F

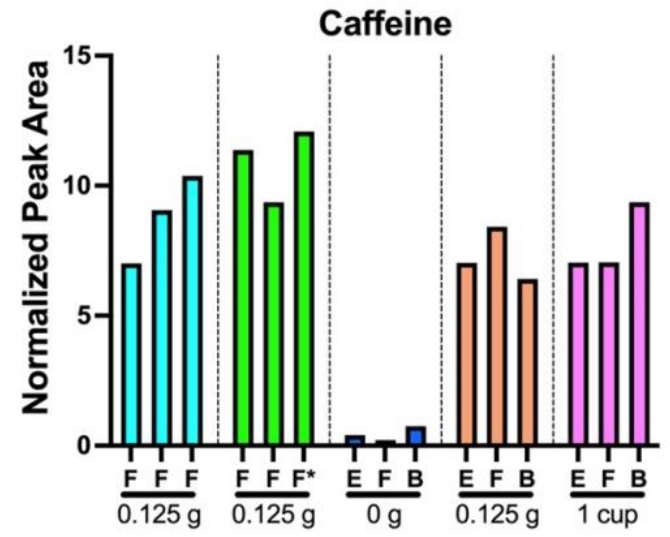


medRxiv preprint doi: https://doi.org/10.1101/2021.08.24.21262320; this version posted January 1, 2022. The copyright holder for this preprint (which was not certified by peer review) is the author/funder, who has granted medRxiv a license to display the preprint in perpetuity.

All rights reserved. No reuse allowed without permission.

Figure 6. Microdialysate samples cluster by patient and pathology.

(A) Spearman correlation map clustered by 181 metabolites (normalized) present in all samples (-1: negatively correlated, 1 : positively correlated).

(B) Spearman correlation map clustered by 15 samples (minimal correlation: 0.7, maximal correlation: 1).

(C) Principal component analysis (PCA) was performed using the full set of 181 named metabolites for the 15 catheter samples grouped by patient. Microdialysate samples from each catheter are shown and categorized by patient. The top two principal components (2D projection) are shown on the $x$ and $y$ axes, respectively.

(D) PCA was performed for the 15 catheter samples grouped by IDH status (mutant or wildtype). Microdialysate samples from each catheter are shown and categorized by samples from patients with IDH-mutant or IDH-wild type tumors. The first two principal components (2D projection) are shown on the $x$ and $y$ axes, respectively.

(E) Sparse Partial Least Squares-Discriminant Analysis (sPLS-DA) for the 15 catheter samples is grouped by patient. The first two components (2D projection) are shown on the $\mathrm{x}$ and $\mathrm{y}$ axes, respectively.

(F) SPLS-DA for the 15 catheter samples is grouped by IDH status. The first two components (2D components) are shown on the $x$ and $y$ axes, respectively. 
medRxiv preprint doi: https://doi.org/10.1101/2021.08.24.21262320; this version posted January 1, 2022. The copyright holder for this preprint (which was not certified by peer review) is the author/funder, who has granted medRxiv a license to display the preprint in perpetuity. All rights reserved. No reuse allowed without permission.
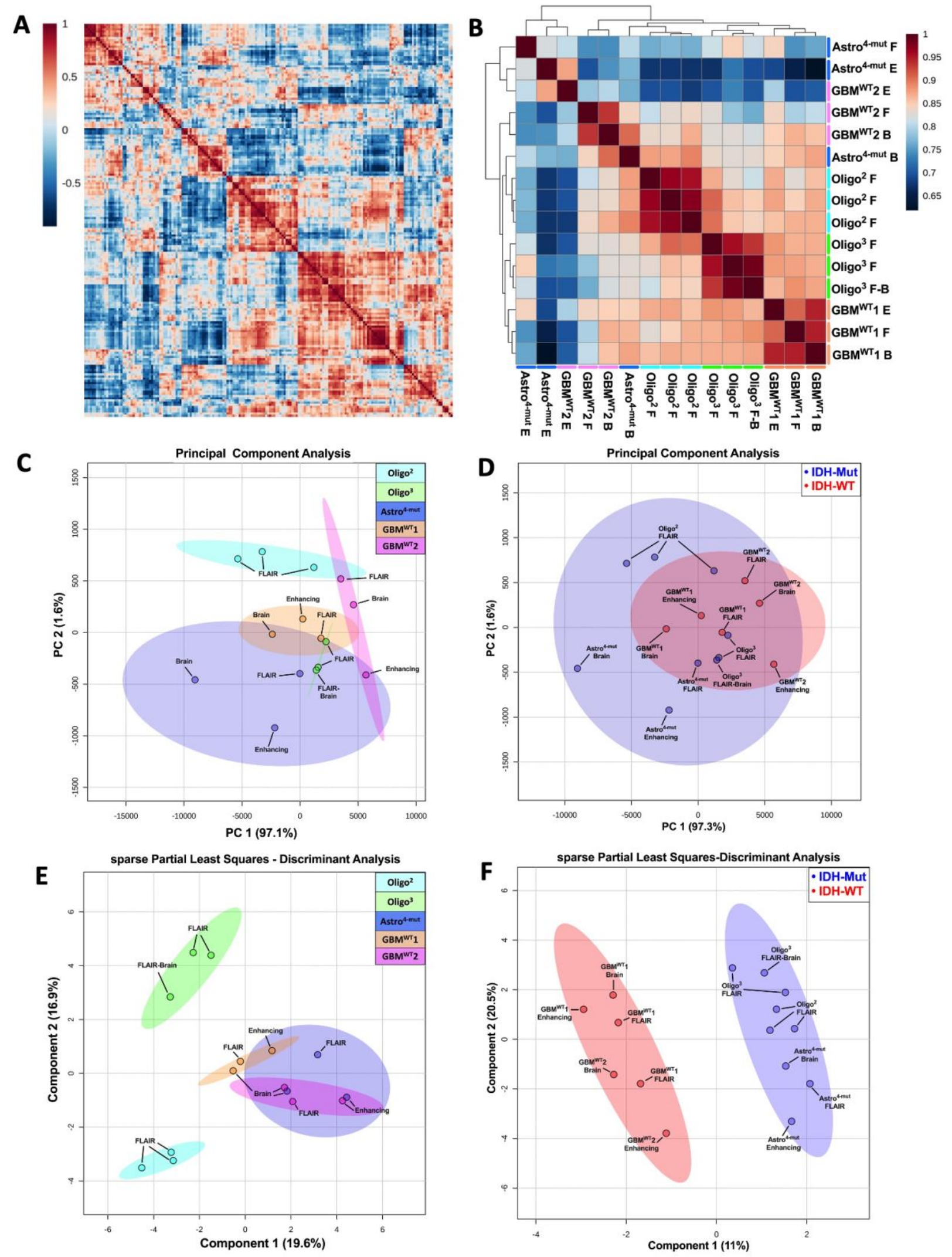